\title{
Natural Variation in Portuguese Common Bean Germplasm Reveals New Sources of Resistance Against Fusarium oxysporum f. sp. phaseoli and Resistance-Associated Candidate Genes
}

\author{
Susana T. Leitão, ${ }^{1, \dagger}$ Marcos Malosetti, ${ }^{2}$ Qijan Song, ${ }^{3}$ Fred van Eeuwijk, ${ }^{2}$ Diego Rubiales, ${ }^{4}$ and Maria Carlota Vaz Patto ${ }^{1}$ \\ ${ }^{1}$ Instituto de Tecnologia Química e Biológica António Xavier, Universidade Nova de Lisboa, Oeiras, Portugal \\ 2 Wageningen University \& Research, Wageningen, The Netherlands \\ ${ }^{3}$ U.S. Department of Agriculture, Agricultural Research Service, Beltsville, MD, U.S.A. \\ ${ }^{4}$ Institute for Sustainable Agriculture, CSIC, Córdoba, Spain \\ Accepted for publication 31 October 2019.
}

\begin{abstract}
Common bean (Phaseolus vulgaris) is one of the most consumed legume crops in the world, and Fusarium wilt, caused by the fungus Fusarium oxysporum f. sp. phaseoli, is one of the major diseases affecting its production. Portugal holds a very promising common bean germplasm with an admixed genetic background that may reveal novel genetic resistance combinations between the original Andean and Mesoamerican gene pools. To identify new sources of Fusarium wilt resistance and detect resistance-associated single-nucleotide polymorphisms (SNPs), we explored, for the first time, a diverse collection of the underused Portuguese common bean germplasm by using genome-wide association analyses. The collection was evaluated for Fusarium wilt resistance under growth chamber conditions, with the highly virulent $F$. oxysporum f. sp.

collection was genotyped with DNA sequencing arrays, and SNPresistance associations were tested via a mixed linear model accounting for the genetic relatedness between accessions. The results from the association mapping revealed nine SNPs associated with resistance on chromosomes Pv04, Pv05, Pv07, and Pv08, indicating that Fusarium wilt resistance is under oligogenic control. Putative candidate genes related to phytoalexin biosynthesis, hypersensitive response, and plant primary metabolism were identified. The results reported here highlight the importance of exploring underused germplasm for new sources of resistance and provide new genomic targets for the development of functional markers to support selection in future disease resistance breeding programs.
\end{abstract} phaseoli strain FOP-SP1 race 6. Fourteen of the 162 Portuguese accessions evaluated were highly resistant and 71 intermediate. The same
Keywords: Fusarium wilt, genetics and resistance, Phaseolus vulgaris
Common bean (Phaseolus vulgaris L.) is the most important food grain legume worldwide, with recognized benefits in health and nutrition (Câmara et al. 2013).

Fusarium wilts reduce the yield of several legume species and other crops (Okungbowa and Shittu 2012). The causal agent of Fusarium wilt disease, Fusarium oxysporum, penetrates through root tips or wounds, growing in the plant vascular system. On susceptible plants, it may lead to vessel clogging, internal stem discoloration, and a rapid yellowing of foliage, followed by defoliation and ultimately plant death. Wilting may be caused by a combination of pathogen activity, such as the accumulation of fungal mycelium or toxin and host defense responses, including the production of gels or gums and vessel crushing (Di Pietro et al. 2003).

†Corresponding author: S. T. Leitão; sleitao@itqb.unl.pt

Current address for M. Malosetti: Nunhems Vegetable Seeds, Nunhem, The Netherlands.

Funding: Financial support was provided by Fundação Para a Ciência e a Tecnologia (FCT), Portugal, grant IF/01337/2014 FCT (Investigator contract M. C. Vaz Patto), research project BeGeQA (PTDC/AGR-TEC/3555/2012), SFRH/ BD/92160/2013 (S. T. Leitão), and research unit GREEN-IT (UID/Multi/04551/ 2013). Short-Term Scientific Missions in the scope of the Horizon 2020 Framework Programme European Framework Programme grants COST-STSM-FA1208-16703 and COST-STSM-FA1306-29560 are also acknowledged.

*The $e$-Xtra logo stands for "electronic extra" and indicates that supplementary materials are published online.

The author(s) declare no conflict of interest.

(C) 2020 The American Phytopathological Society
In common bean, Fusarium wilt is caused by $F$. oxysporum (Schlecht) f. sp. phaseoli Kendrick \& Snyder (Agrios 1997) and is among the most important fungal diseases affecting common bean production throughout the world (Alves-Santos et al. 2002; NiñoSánchez et al. 2015; Schwartz and Pastor-Corrales 1980; Toledo Souza et al. 2012; Xue et al. 2015). At least six different races of $F$. oxysporum $\mathrm{f}$. sp. phaseoli have been described (Alves-Santos et al. 2002; Salgado et al. 1995), generally associated with a specific geographic area. Race 1 includes isolates found both in the United States and Italy; race 2, isolates found in Brazil; race 3, isolates found in Colombia; race 4, isolates found in the United States; race 5, isolates found in Greece; and race 6, isolates found in Spain. In Portugal, there is no history of the predominant $F$. oxysporum $\mathrm{f}$. sp. phaseoli races in the fields, but because of the country's geographic proximity to Spain, one may expect that $F$. oxysporum f. sp. phaseoli race 6 isolates may also be affecting common bean yields in Portugal.

Controlling vascular wilt pathogens is not an easy task. Chemical fungicides are ineffective, especially for pathogens such as $F$. oxysporum f. sp. phaseoli that have a soilborne nature and possess structures that persist for long periods in the soil, even in the absence of host plants (Yadeta and Thomma 2013). Also, biological control using antagonistic bacteria or fungi cannot limit these vascular diseases effectively, because abiotic and biotic factors make their performance inconsistent. Consequently, the use of resistant cultivars is the most efficient, environmentally friendly, and economically viable strategy to provide effective Fusarium wilt disease control (Dodds and Rathjen 2010).

A better understanding of the genetic basis of resistance mechanisms deployed by resistance sources is needed for more efficient resistance breeding, taking into consideration the 
pathogen's evolutionary potential. In common bean, the $F$. oxysporum f. sp. phaseoli resistances already described are controlled by either single major genes or polygenes according to the common bean geographic and genetic origin (Batista et al. 2017; Cross et al. 2000; Fall et al. 2001; Salgado et al. 1995). Because $F$. oxysporum populations are not very large because of its low potential for gene flow, asexual reproduction, and low mutation rate, the use of major resistance genes in breeding might be a sufficient strategy to achieve durable resistance, provided that virulence is monitored and genes deployed spatially (McDonald and Linde 2002). Nevertheless, because the fungus may be seedtransmitted, the risk of gene flow because of human activities is high. Under these circumstances, pyramiding of different major genes with the complementary use of quantitative incomplete resistances is advisable. In this way, the continuous search for new sources of resistance is essential for developing and deploying more durable resistances on new cultivars.

In Portugal, common bean represents about $70 \%$ of grain legumes consumed by humans (Estatísticas Agrícolas 2017, https://www. ine.pt/). A very diverse common bean germplasm, resulting from $>500$ years of cultivation and adaptation to the country's edaphoclimatic conditions, is still preserved in farmers' fields but underexploited by conventional breeding. An extended representative collection of this national diversity was recently characterized (Leitão et al. 2017). Genetic structure analysis divided this collection into three main clusters, one more related to the Mesoamerican gene pool and two more related to the Andean gene pool. Most of the Portuguese germplasm analyzed grouped with the Andean region race representatives and wild relatives. However, one third of the national germplasm had an admixed origin and might represent putative hybrids between the original Andean and Mesoamerican gene pools.

As a result of co-evolutionary interactions between pathogens and their host plants, virulent isolates for each common bean gene pool have evolved. Accordingly, common bean resistance genes of Mesoamerican origin are more effective when transferred to bean varieties with Andean background and vice versa (Geffroy et al. 1999; Guzman et al. 1995; Miklas et al. 2006; Mkandawire et al. 2004). Thus, besides the resistance genes that may be detected in the Portuguese germplasm of Andean origin, the Portuguese gene pool admixed accessions may have novel resistance gene combinations, harder for the pathogen to overcome and therefore useful to increase the durability of resistance. However, little is known about the response of the Portuguese germplasm against $F$. oxysporum f. sp. phaseoli. To the best of our knowledge, only one short report exists characterizing two Portuguese common bean cultivars (Tarrestre and Oriente) as very susceptible to a $F$. oxysporum f. sp. phaseoli strain (FA-15) isolated from a greenhouse in Portugal (Santos et al. 2017). Nevertheless, the genetic diversity found by Leitão et al. (2017) on the Portuguese common bean germplasm encouraged the exploitation of the natural variation for Fusarium wilt resistance that might exist in a larger number of Portuguese accessions.

Until now, only a few biparental linkage mapping-based reports are available on common bean resistance to Fusarium sp., namely $F$. oxysporum f. sp. phaseoli (Fall et al. 2001) and $F$. solani f. sp. phaseoli (Hagerty et al. 2015; Nakedde et al. 2016). However, these studies were limited to the allelic diversity that segregates between the parental lines used in the cross, which eventually also restricts mapping resolution (Korte and Farlow 2013).

Genome-wide association studies (GWASs) are a powerful tool to identify polymorphisms underlying natural variation in genomic regions responsible for the expression of a given trait. This approach can provide higher-resolution mapping, greater allelic diversity, and greater efficiency and accuracy in estimating marker effects for quantitative traits than biparental linkage mapping (Myles et al. 2009). GWASs have been successfully applied in common bean to analyze the genetic control of resistance to several diseases such as anthracnose, angular leaf spot, and bacterial blight (Choudhary et al. 2018; Perseguini et al. 2016; Wu et al. 2017; Zuiderveen et al. 2016).
The present study was designed to explore the Portuguese common bean natural variation to identify resistance against Fusarium wilt and to detect SNP-resistance associations by using a GWAS approach. For that, we evaluated a collection of 162 Portuguese common bean accessions for resistance to Fusarium wilt under controlled conditions and performed a high-throughput SNP screening of the same collection. SNP-trait associations were tested via a mixed linear model accounting for the genetic relatedness between accessions to identify the genomic regions controlling Fusarium wilt resistance. To our knowledge, this is the first time a GWAS has been applied to a Portuguese common bean collection and for common bean Fusarium wilt resistance.

\section{MATERIALS AND METHODS}

Phenotypic data. Plant material and growing conditions. One hundred sixty-two Portuguese common bean accessions, belonging to the national $P$. vulgaris germplasm collection, were used in this study. A complete list of the accessions studied along with their passport information is available in Supplementary Table S1. Two Mesoamerican lines, SER16 and Tio Canela-75, kindly provided by the Centro Internacional de Agricultura Tropical (CIAT, Colombia) were also evaluated as international references for comparative purposes. SER16 is an improved bean line for drought resistance (Polania et al. 2016a), and Tio Canela-75 is a commercial variety noted for its resistance to bean golden mosaic virus, common bacterial blight, rust, and heat tolerance (Rosas et al. 1997). No previous information on the resistance levels of these accessions to Fusarium wilt was available.

Common bean seeds were surface sterilized for $20 \mathrm{~min}$ in a $20 \%$ solution of sodium hypochlorite, rinsed two times with sterile water for $20 \mathrm{~min}$, and sown in 0.5 liter pots filled with sterile vermiculite (1 to $3 \mathrm{~mm}$ in diameter). One seed was sown per pot, and three to five pots per accession were used. Pots were placed in a growth chamber kept at $27 \pm 2{ }^{\circ} \mathrm{C}$ under a photoperiod of $14 \mathrm{~h}$ light (approximately $250 \mu \mathrm{mol} / \mathrm{m}^{2} / \mathrm{s}^{-1}$ ) and $10 \mathrm{~h}$ dark, and with a relative humidity of 60 to $70 \%$. In total, 1,033 plants were evaluated.

Experimental design. Because growth chamber space constraints, we used an incomplete block design, and the 164 accessions (162 Portuguese, SER16, and Tio Canela-75) were assigned to three independent blocks or experiments. Three to five plants (average 4.5) per accession were evaluated in each experiment and averaged. To correct for the block (experiment) effect, 30 accessions were repeatedly evaluated in all experiments. Additionally, in each of the three experiments, three extra plants from eight accessions under evaluation ( 24 plants in total per experiment) were randomly chosen and used as noninoculated controls for symptom comparison.

Fungal isolate and cultural conditions. F. oxysporum f. sp. phaseoli isolate FOP-SP1 race 6 was kindly provided by José María Díaz Mínguez (University of Salamanca, Spain) and stored as microconidial suspensions at $-80^{\circ} \mathrm{C}$ in $30 \%$ glycerol, for use in all experiments. This fungal strain was identified in common bean cultivars in Avila, Spain, and classified as highly virulent (AlvesSantos et al. 2002).

For microconidia multiplication, a protocol adapted from Haglund (1989) and Lichtenzveig et al. (2006) was followed. Briefly, the fungal culture was grown in the dark at $28^{\circ} \mathrm{C}$ under constant shaking (170 rpm) for 4 days, filtered through autoclaved cheesecloths to separate both microconidia and macroconidia from F. oxysporum mycelium and centrifuged at $6,000 \mathrm{rpm}$ for $10 \mathrm{~min}$ at room temperature. The conidial pellets were resuspended, and a suspension of $5.0 \times 10^{6} \mathrm{conidia} / \mathrm{ml}$ was prepared to be used on the same day to inoculate the common bean seedlings.

Inoculation and disease assessment. For inoculation, 7-day-old seedlings were removed from the pots, vermiculite was cleaned from the roots, and the roots were then trimmed by a third and immersed for $5 \mathrm{~min}$ in the conidial suspension previously prepared, 
following a modified version of the dipping technique described by Haglund (1989). The noninoculated control plants were similarly trimmed by a third, but roots were immersed in sterile water instead of conidial suspension. Seedlings were replanted in the pots and maintained in the same growth chamber, under the same photoperiod and temperature conditions. All plants were well watered during the experiment with tap water, and once a week they were irrigated with Hoagland nutrient solution (Hoagland and Arnon 1938).

Symptoms were assessed at leaf level every 3 days, from the seventh to the 30th day after inoculation (DAI), a total of eight time points, on a disease severity (DS) visual scale ranging from 1 (healthy leaf) to 5 (dead leaf) (adapted from Bani et al. (2012) and Rispail and Rubiales (2014)). In more detail, $1=$ no symptoms; $2=$ light to moderate chlorotic symptoms; 3 = leaves completely chlorotic and bright yellow; $4=$ chlorotic leaves with wilt and necrosis symptoms; and $5=$ leaves and branches exhibiting wilt, chlorosis, necrosis, and defoliation, eventually with plant death (Fig. 1). Intermediate scale values were given when appropriate. At 30 DAI, accessions were considered resistant if they had a mean DS score (DS30) of 1, intermediate if they had a mean DS score of 2 or 3, and susceptible if they had a mean DS score of 4 or 5 .

The progression of Fusarium wilt disease was monitored, and DS scores taken per plant at the eight time points were averaged per accession and plotted. Then, a linear regression was fitted to obtain the disease progress rate (DSr) given by the slope of the regression line. The accessions were grouped according to the disease progression profile obtained by the eight time points, and four trends were observed: accessions that maintained a low DS (1) along $30 \mathrm{DAI}$; accessions that reached and maintained an intermediate DS score (2 to 3 ); accessions that reached a high DS score (4 to 5) in the first 2 weeks of evaluation; and accessions that reached a high DS score (4 to 5) only 16 DAI or later.

To combine the multiple observations of Fusarium wilt disease progress taken over time for each accession into a single value, the area under the disease progress curve (AUDPC) was calculated per plant, and then averaged per accession, via the following formula:

$$
\mathrm{AUDPC}=\Sigma\left[\left(x_{i}+x_{i+1}\right) / 2\right] *\left(t_{i+1}-t_{i}\right)
$$

where $x_{i}=$ score of disease severity at time $i, x_{i+1}=$ score of disease severity at time $i+1$, and $t_{i+1}-t_{\mathrm{i}}=$ number of days between scoring times $i$ and $i+1$. AUDPC scores provided a quantitative summary of Fusarium wilt disease severity over 30 DAI for each accession, joining the progression with the extent of disease severity data assessed at multiple observations. Therefore, the higher the AUDPC value, the more susceptible the accession.

Phenotypic data analysis. The results from the three traits DS30, AUDPC, and DSr (disease progress rate) were compared via Pearson linear correlation.

To increase the accuracy and repeatability of the association study, the accessions showing DS30 and AUDPC standard deviations $>1.5$ and 25 , respectively, were excluded from the GWAS analysis. This resulted in the removal of 14 accessions.
The linear mixed model applied was trait (Fusarium wilt DS30, AUDPC, DSr) = accession + block + error. The assumptions of normal errors and homogeneous error variance were checked. Accession is the genotypic term and block is the term that identifies the three experiments needed to have all 150 accessions evaluated. With the 30 accessions that were repeatedly evaluated in the three experiments, the experimental effect was estimated. In a first step, the model was fitted with all terms at random to obtain the best linear unbiased predictors. A restricted maximum likelihood (REML) procedure was conducted to estimate the variance components of the linear mixed model and the broad-sense heritability. In a second step, accessions were fitted as a fixed term, and the best linear unbiased estimates (BLUEs) for each accession and trait were produced and used as input phenotypic data in the association mapping analysis. All analyses were performed in Genstat software, 19th edition (VSN International 2017).

Genotypic data. DNA from one representative individual per accession was isolated from young leaves with a DNA purification kit. The criteria to select the representative individuals were described in a previous work from our team (Leitão et al. 2017). DNA quantification was performed at $260 \mathrm{~nm}$ with a spectrophotometer, and the concentration of all samples was set to values between 50 and $100 \mathrm{ng} / \mu \mathrm{l}^{-1}$, in a volume of $30 \mu \mathrm{l}$. Wavelength ratios of 260/230 and $260 / 280 \mathrm{~nm}$ were examined to assess DNA purity. The DNA quality was also checked in $0.8 \%$ agarose gels stained with cyanine dye.

DNA samples were genotyped with a high-throughput molecular assay containing 5,398 SNPs, designed based on the sequence of $P$. vulgaris 14x and v0.9 de novo assemblies (Song et al. 2015), and Diversity Arrays Technology sequencing (Kilian et al. 2012).

Genotypic data analysis. Quality control. Genotypic data quality control was performed by removing SNP markers and accessions with $>25 \%$ missing data. SNPs called as heterozygous were set as missing data. Moreover, markers with a minor allele frequency $<0.01$ were removed.

Genetic structure. A subset of 454 SNP markers evenly distributed throughout the common bean genome (average distance between markers of 1.1 Mbp) was used to build a similarity matrix to estimate pairwise genetic relatedness among the accessions, as implemented in Genstat software, to calculate principal coordinate scores to study the population structure. The obtained SNP-based structure was compared with the three clusters (Mesoamerican related, Andean related, and admixture nature) identified previously using simple sequence repeats (SSRs) in the same collection (Leitão et al. 2017).

Association mapping. GWASs to reveal Fusarium wilt DS30, AUDPC, and DSr-associated SNPs were conducted via the quantitative trait locus (QTL) library procedures available in Genstat software. The adjusted means (BLUEs) of the three traits were tested for association with 9,825 SNP markers scored in 133 common bean accessions that passed the genotypic and phenotypic quality filters applied.

The association mapping was performed in the mixed-model framework of Genstat software, using the model phenotype $=\mathrm{SNP}+$ genotype + error, fitting SNP as fixed and genotype as random terms
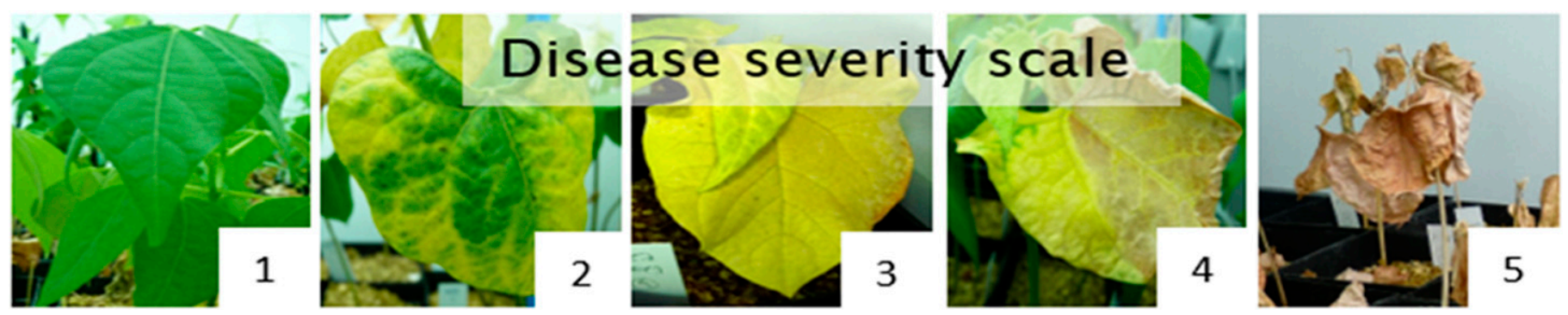

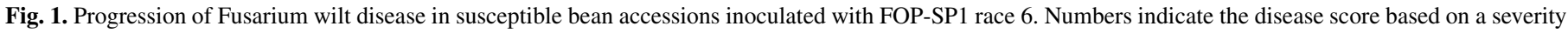
scale ranging from 1 (healthy leaf) to 5 (dead leaf). 
via REML (Malosetti et al. 2007), with genotype random effects structured following a kinship matrix. For each chromosome, a different kinship matrix was calculated by using only the SNPs located on the remaining 10 chromosomes, as proposed by Cheng et al. (2013). The procedure was performed with the kin function of $\mathrm{R}$ package synbreed (Wimmer et al. 2012) and the VanRaden measure (VanRaden 2008). The genome-wide marker-trait association scan was conducted by testing the significance of the marker effect via a marginal Wald test at each SNP location. The observed $-\log _{10}(P$ value $)$ of each SNP was plotted against their chromosomal positions to produce a Manhattan plot. At a threshold level of $-\log _{10}$ ( $P$ value $)=3$, the significant marker-trait associations were depicted. This threshold was set to discard the background noise obtained in the Manhattan plot without compromising the identification of potentially interesting regions, which would be missed by the overly stringent and conservative Bonferronicorrected threshold of significance. However, as a "conservative" guidance, two additional approaches were followed. On one hand, a linkage disequilibrium (LD)-adjusted Bonferroni-corrected threshold $(\alpha / k)$, considering an $\alpha=0.05$ and setting the effective number of independent tests as the number of LD blocks per chromosome $(k=520)$, was calculated (Duggal et al. 2008). Additionally, adjusted $P$ values following the Benjamini and Yekutieli false discovery rate method (Benjamini and Yekutieli 2001) were calculated, in this case with $\alpha=0.2$ and $k=520$, to control type I errors caused by multiple testing.

For every SNP significantly associated with Fusarium wilt DS30, AUDPC, and DSr progress rate, the effect of the allele variant in relation to the most frequent allele was calculated. The proportion of variance explained by each SNP-trait association was estimated via the formula:

$$
V_{\mathrm{QTL}}=V_{\text {pheno }}
$$

where $V_{\mathrm{QTL}}=2$ freq $(1-$ freq $)$ effect ${ }^{2}$ and $V_{\text {pheno }}$ is the phenotypic variance of the adjusted means of each trait (Resende et al. 2017). The relation between the frequency of each trait-associated SNP allele, the resistance level, and the gene pool of origin of the accessions (Leitão et al. 2017) was also investigated.

Local linkage disequilibrium and candidate gene identification. A gene was considered a putative candidate gene for Fusarium wilt DS30, AUDPC, or DSr progress rate if it contained a significant associated SNP (threshold for significance $-\log _{10}[P] \geq 3$ ) or if it was in LD with an SNP significantly associated with the trait. LD was calculated for each chromosome as a measure of the recombination history, using the squared coefficient of correlation between marker pairs, $r^{2}$, after correcting for population structure with the principal component scores from Eigenanalysis, as implemented in Genstat software. For this calculation, the entire set of SNPs was used. Average intrachromosomal LD decay per chromosome was visualized by plotting $r^{2}$ against the physical mapping distance in Mbp. To consider the existence of adjacent SNP markers in LD with the ones identified as significantly associated with the trait, the $r^{2}$ of the neighboring SNPs was investigated, bearing in mind a strict threshold of LD decay $\left(r^{2}>0.2\right)$. The location of these adjacent SNPs in LD with the significantly associated ones was used to define an LD block and to browse for putative candidate genes mapped in those genomic regions.

The common bean genome sequence, from the Andean common bean accession G19833 (Schmutz et al. 2014), was investigated with the JBrowse tool in Phaseolus vulgaris v2.1, available at the Phytozome v12 portal (DOE-JGI and USDA-NIFA, https://phytozome.jgi.doe.gov/). The functional annotation of the genes under the identified genomic regions was given by KEGG/KOG/PFAM/ PANTHER/Gene Ontology database identifiers, which were used to make inferences about the pathways involved and the possible role of the common bean candidate genes in the control of Fusarium infection.

\section{RESULTS}

Fusarium wilt disease severity variation. To determine the progression of Fusarium wilt symptoms among the common bean accessions, disease severity (DS) was scored eight different times during 30 DAI. By 10 DAI, 29 accessions presented leaves already completely chlorotic, with visual symptoms of necrosis, and were classified as DS4 (susceptible), whereas 64 accessions still displayed DS1 (resistant) and 71 DS2 to 3 (intermediate). At 20 DAI, all five DS scoring values were found among the collection, showing the variability of responses among the Portuguese common bean germplasm. By 30 DAI, 78 accessions displayed DS4 to 5, with 55 of them dead. The Mesoamerican line Tio Canela-75 was included in this group (DS4). On the other hand, at this final time point, 14 accessions (9\%) were considered completely resistant (DS $\leq 1.5)$ and 72 accessions (44\%) were considered intermediate, with leaves showing different levels of chlorosis but no necrosis (DS2 to 3) (Fig. 2). This last group included the Mesoamerican line SER16 (DS3).

Additionally, the eight DS scores per accession were plotted (Supplementary Fig. S1). Of the 78 susceptible accessions, 60 reached a high DS score (4 to 5) in the first 2 weeks after inoculation, whereas 18 only showed high DS scores 15 DAI or later. On the other hand, the 14 accessions considered resistant (DS $\leq 1.5$ ) maintained the low DS score during the entire experimental time frame. Finally, the 70 intermediate accessions reached and maintained DS values between 1.6 and 3.5. Fusarium wilt progress rate (DSr), given by the slope of the DS score regression, ranged from 0.000 (resistant accession) to 0.571 (susceptible accession) (Supplementary Table S2).

With the Fusarium wilt DS values scored every 3 days during 30 DAI, the AUDPC was calculated for each accession and their frequency distribution plotted (Fig. 3).

Fusarium wilt AUDPC mean values per accession ranged from 27.8 to 105.1. The frequencies of AUDPC classes followed a bimodal distribution, with two AUDPC peaks, indicating a clear discrimination between resistant (low AUDPC values) and susceptible (high AUDPC values) accessions. Accessions having an AUDPC value $<30$ were regarded as resistant, those with AUDPC between 31 and 69 intermediate, and those with AUDPC $>70$ susceptible. A complete list of AUDPC values per accession is available in Supplementary Table S3.

The 14 accessions considered resistant - simultaneously with DS $\leq 1.5$, AUDPC $<30$, and DSr $<0.100$ - were of either Andean or admixed origin. Nevertheless, in the intermediate and susceptible accessions, it was possible to identify both Andean and Mesoamerican gene pools in addition to the admixed origin (Fig. 4 and Table 1).

Pearson coefficients revealed strong pairwise correlations between DS measured at 30 DAI (DS30), AUDPC, and DSr (Table 2).

Phenotypic data variance components and broad sense heritability. The examination of the histogram of residuals, residuals versus fitted values of the model and the expected versus normal quantiles (Q-Q) plot revealed a random pattern of residuals for the three traits (DS30, AUDPC, and DSr) further used in GWASs (Supplementary Fig. S2).

The REML estimators of the variance components of the linear model were obtained with accession and block as random terms and broad-sense heritability, calculated as the ratio of genotypic variance to total phenotypic variance (genetic plus error) (Table 3 ). With accession term fixed, Wald statistics indicated very strong evidence for differences between accessions $(P$ value $<0.001)$ for DS30 and AUDPC, and less strong but still significant differences between accessions for DSr $(P$ value $=0.003)$.

Association panel genetic structure. Based on the 454 selected SNP markers, two main groups of accessions were visualized via principal coordinate analysis (Fig. 5). The variance 
explained by the first two principal coordinates was $65.71 \%$. The observed clustering on the 133 Portuguese accessions was in accordance with their genetic proximity to the two original common bean gene pools in Mesoamerica and in the Andes. Intermediate resistant and susceptible accessions were identified within the accessions more related to the Andean and Mesoamerican gene pools and also among the accessions of admixture origin, whereas the resistant accessions were all of Andean or admixed origin.

Marker-trait associations. A high-throughput molecular assay and Diversity Arrays Technology sequencing genotyped together 16,689 SNPs. After quality control, a total of 9,825 SNPs and 133 accessions were used in the association mapping study.

For the three traits under analysis-Fusarium wilt disease severity at 30 DAI (DS30), AUDPC, and disease progress rate (DSr) - the distribution of the $-\log _{10}(P$ values $)$ from marginal Wald tests was investigated by Q-Q plots (Supplementary Fig. S3). Some deflation of the test statistic was observed $(P$ values are slightly under the expected $y=x$ line), but the points corresponding to the significant associations clearly stand out at the high end of the plots (Supplementary Fig. S3).

The results from the association mapping revealed nine SNPs significantly associated (with $-\log _{10}[P] \geq 3$ ) with resistance on chromosomes Pv04, Pv05, Pv07, and Pv08 (Fig. 6 and Table 4). The LD-adjusted Bonferroni-corrected $P$ value set the threshold as $-\log _{10}(P)=4.0$. The use of this threshold would render the previously detected associations as suggestive. The BenjaminiYekutiely $P$ value adjustment was found to be highly stringent for all associations.

By inspecting the allelic variant effect on Fusarium wilt resistance of the associated SNPs, it was possible to identify the most promising SNPs for marker-assisted selection (SNPs strongly associated and with higher effect on trait variation). Nevertheless, each of the SNP-trait associations identified for DS30, AUDPC, and DSr explained only a small portion of the observed phenotypic variance (Table 4).

From the seven significant associations detected for both Fusarium wilt DS30 and AUDPC on chromosomes Pv04, Pv07, and Pv08 (Fig. 6), DART03480 on chromosome Pv04 had the highest $-\log _{10}(P)$ of 3.79 and 3.84 , respectively. The associated SNPs that explained the biggest proportion of variance $(7.18 \%$ in DS30 and 7.02\% in AUDPC) were SNP03304 and SNP03306 on chromosome Pv07 (Table 4).

The allelic variant of four of these seven associated SNPs caused a negative effect in Fusarium wilt DS30, in relation to the most frequent allele, meaning that they contributed to an increase in disease resistance. The absolute value of the allelic variant effect for all the DS30-associated SNPs was close to 0.5 in the DS score scale. This corresponded to an increase (or decrease for the SNPs whose allelic variant had a negative effect) in $15 \%$ to the DS30 mean value (3.2) of the collection.

Similarly to DS30, the allelic variant of the associated SNPs located on chromosomes 7 and 8 caused a negative effect in Fusarium wilt AUDPC, contributing to an increase in Fusarium wilt disease resistance. The absolute value of the allelic variant effect for all the AUDPC-associated SNPs was close to 11 AUDPC units. This corresponded to an increase (or decrease for the SNPs whose allelic variant has a negative effect) in $17 \%$ to the AUDPC mean value (63) of the collection.

The SNPs associated with Fusarium wilt progression rate (DSr) on chromosome Pv07 were the same associated with DS30 and AUDPC. However, the two associations on chromosome Pv05 were unique for DSr. From the five associations detected for DSr (Fig. 6), DART04561 on chromosome Pv05 had the highest $-\log _{10}(P), 3.40$. This SNP also explained the biggest proportion of variance $(6.44 \%)$ in this trait (Table 4).

All allelic variants of four out of five associated SNPs caused a negative effect in Fusarium wilt DSr, in relation to the most frequent allele, meaning that they contributed to a decrease in the disease progress rate. The exception was DART04561, with a positive effect in DSr. The absolute value of the allelic variant effect for all DSr-associated SNPs was close to 0.05 . This value corresponds to a decrease in $19 \%$ to the DSr mean value $(0.264)$ of the collection.

SNP allelic variant frequency among gene pool of origin of accessions. The frequency of the favorable allele (providing an increase in resistance) in the nine associated SNPs was different in

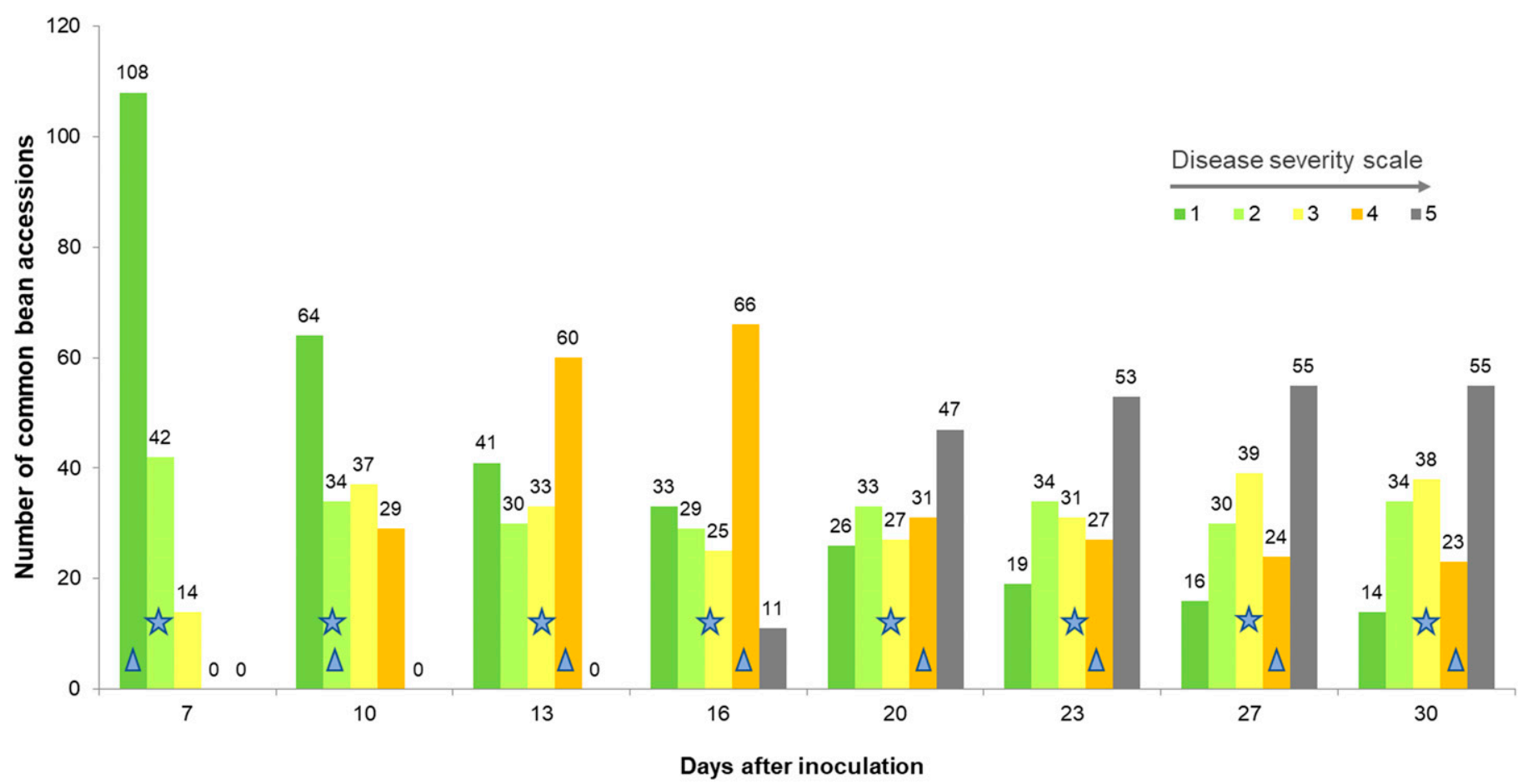

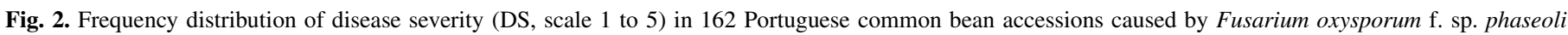

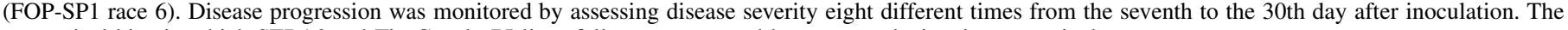
categorical bins in which SER16 and Tio Canela-75 lines fall are represented by a star and triangle, respectively. 
the gene pool of origin of the Portuguese accessions (Fig. 7). The accessions of Mesoamerican origin had, on average, a higher frequency of the favorable alleles than the ones of Andean origin for the SNPs associated with chromosomes Pv04 and Pv07. The most contrasting frequency values were observed for SNP02051, located on chromosome Pv05, for which the frequency of the favorable allele was much higher (0.72) in the accessions of Mesoamerican origin than in the accessions of Andean or admixed origin (frequency $=0.20$ ). On the other hand, the favorable alleles of DART07926 associated with chromosome Pv08 and DART04561 on chromosome Pv05 were more frequent in the accessions of Andean origin. The average frequency of the favorable allele in the accessions of admixture origin was in most cases intermediate between the accessions of Andean and Mesoamerican origin. Additionally, the frequency of the favorable allele was always $>0.75$ for the associated SNPs located on chromosome Pv04, regardless of the gene pool of origin of the accessions.

Candidate gene identification. The LD decay to $r^{2}=0.1$ per chromosome varied from 0.5 (on chromosome Pv07) to $1.8 \mathrm{Mbp}$ (on chromosome Pv09), with an average graphically estimated of 1.1 Mbp. Supplementary Figure S4 shows the LD decay, measured as $r^{2}$ values versus marker distance, and shade plots per chromosome with the correlation between markers highlighted with a color range code.

After the SNPs significantly associated with Fusarium wilt response-using the traits AUDPC, disease severity at 30 DAI (DS30), and disease progress rate (DSr) — and the neighboring SNPs in LD were identified, their locations were used to search for putative candidate genes in the $P$. vulgaris genome v2.1. Candidate genes were identified for six of the nine SNP-trait associations (Table 5).

Of the six candidate genes identified, two (Phvul.004G006800 and Phvul.007G270000) encoded proteins involved in the inducible plant response to pathogens, such as phytoalexin biosynthesis and hypersensitive reaction. The others were related to amino acids and secondary metabolite biosynthesis (Phvul.004G000800), precursor
mRNA splicing (Phvul.007G270500), signaling of plant immune receptors (Phvul.008G196600), and plant translational regulation and stress adaptation (Phvul.008G203200).

\section{DISCUSSION}

The continuous search for new sources of resistance in underexplored plant germplasm collections and the study of their genetic basis is essential for the development of tools to support the breeding of new common bean cultivars with durable resistance to Fusarium wilt. By exploring the natural variation of 162 accessions representative of the Portuguese common bean germplasm, we found 14 new sources of complete resistance and 71 new sources of incomplete resistance against the highly virulent $F$. oxysporum $\mathrm{f}$. sp. phaseoli isolate FOP-SP1 race 6. Complete and incomplete resistant sources were identified among accessions of Andean, Mesoamerican, and genetic admixed origin that constitute the Portuguese germplasm.

Additionally, we identified nine SNPs with small effects associated with this natural variation and six candidate genes, suggesting an oligogenic control of the detected resistances. The identified favorable SNP alleles controlling Fusarium wilt resistance will facilitate the resistance transfer into more productive elite cultivars in marker-assisted breeding schemes.

As far as we know, this was the first time that sources of resistance to this particular $F$. oxysporum $\mathrm{f}$. sp. phaseoli isolate, classified as one of the most virulent in a pathogenicity screening of 16 isolates from Spain and Greece (Alves-Santos et al. 2002), were identified in European common bean germplasm. This was also the first GWAS dedicated to common bean Fusarium wilt response and the first report of a GWAS using a panel of Portuguese common bean germplasm.

Different responses were detected among the Portuguese common bean accessions when they were inoculated with FOPSP1 race 6, revealing the high variation present in the collection. Thirty days after inoculation, the accessions were categorized from

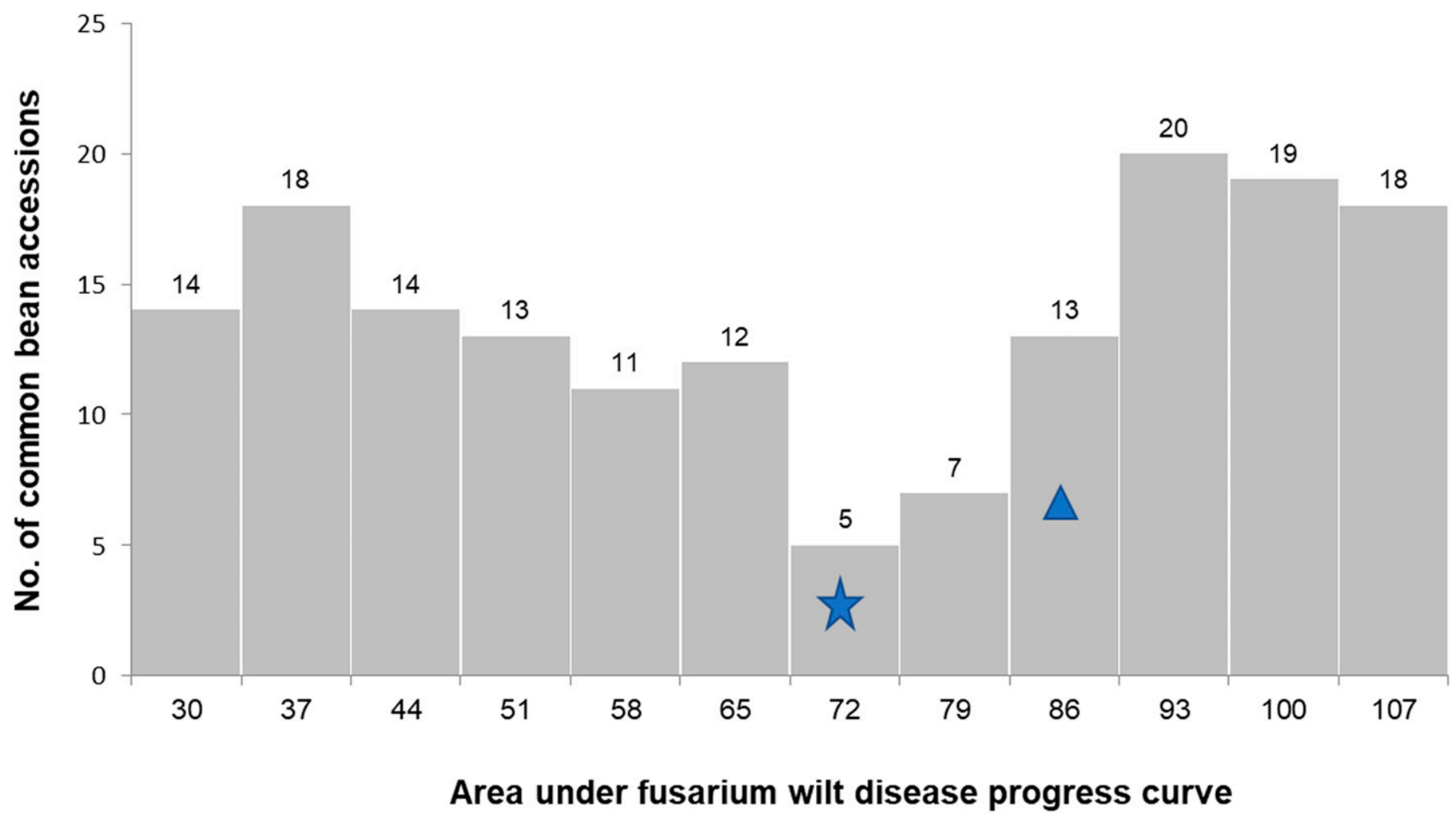

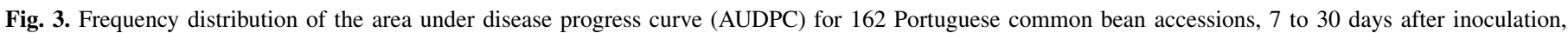

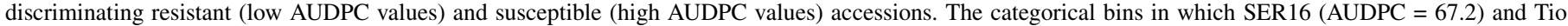
Canela-75 (AUDPC $=80.4$ ) lines fall are represented by a star and triangle, respectively. 
completely resistant (9\%) to susceptible (48\%), with many intermediate cases $(43 \%)$ that showed leaves with chlorosis that did not progress to necrosis. Two patterns of disease progression were observed among the susceptible accessions: a fast disease progress rate with accessions reaching high disease severity scores ( 4 to 5) in the first 2 weeks after inoculation and a slower disease progression with accessions reaching the same high scores but only 16 DAI or later. There is a lack of information on how and where this delay takes place in the host-pathogen interaction (Garcés-Fiallos et al. 2017). In the case of the resistant accessions, no external disease symptoms were observed, and they kept their green leaves and typical development throughout the experiment. Resistant and intermediate accessions have been described as either chemically inhibiting the hypha growth or physically blocking the conidia spreading up the sap stream (Abawi and Pastor Corrales 1990;
Garcés-Fiallos et al. 2017; Niño-Sánchez et al. 2015; Xue et al. 2015). This impairment may occur through the formation of papilla structure, cell wall strengthening, and vessel crushing, as it was described for other legume species (Bani et al. 2018; Cachinero et al. 2002; Castillejo et al. 2015; Grayer and Kokubun 2001). A histological analysis will be needed in the identified common bean resistant accessions to elucidate the underlying physiological mechanisms.

The identification of new sources of resistance to this common bean disease is of extreme importance because the existing ones provide only moderate or incomplete levels of protection to specific F. oxysporum f. sp. phaseoli races isolates (Buruchara and Camacho 2000; Pereira et al. 2013; Salgado et al. 1995; Schwartz and Otto 2005). Moreover, previous studies on widely cultivated Spanish common bean cultivars (of Andean origin), and on other cultivars

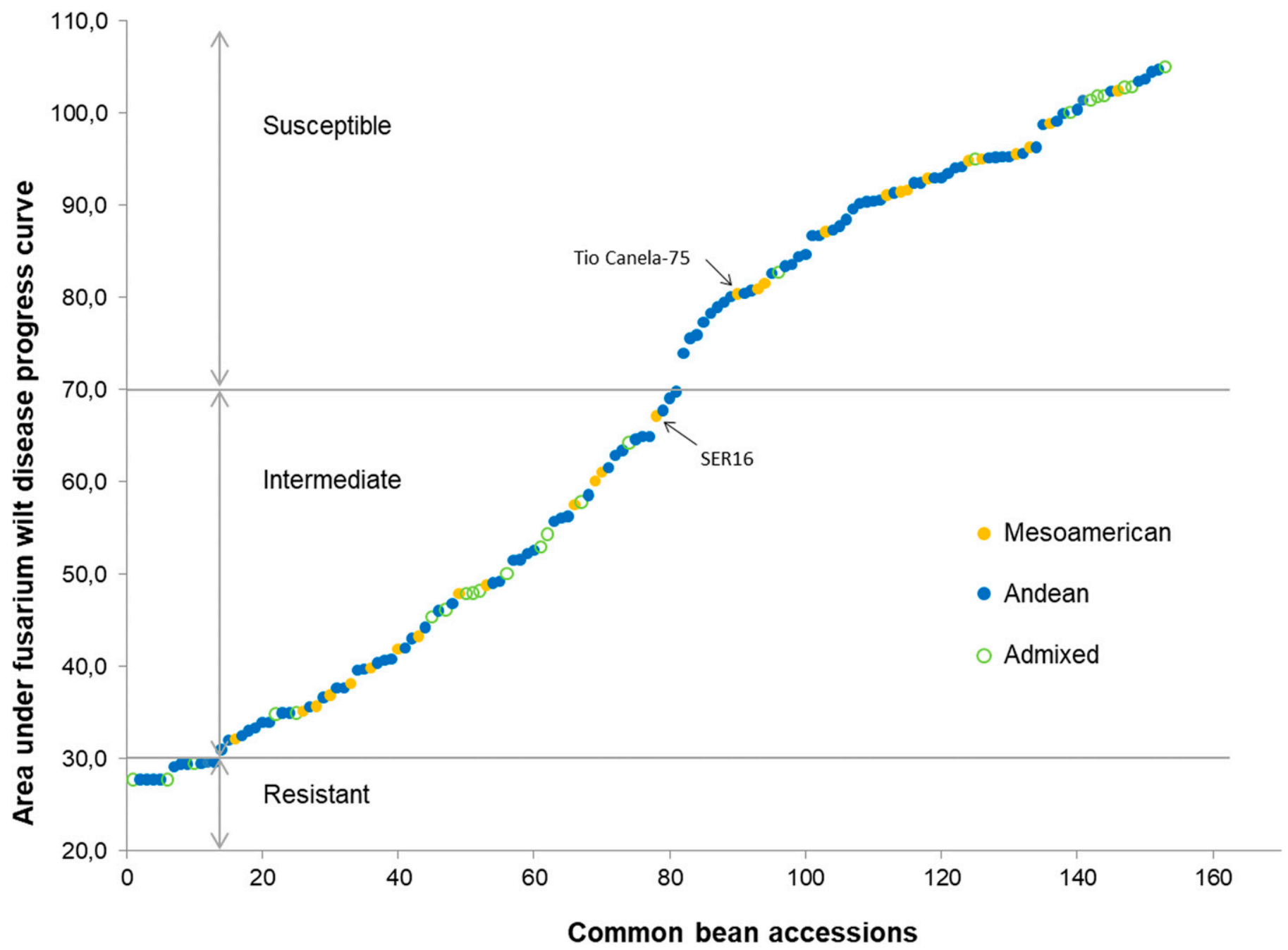

Fig. 4. Fusarium wilt area under disease progress curve (AUDPC) values of the Portuguese common bean accessions. The accessions are colored according to the clustering resulting from the structure analysis performed together with gene pool representatives (Leitão et al. 2017). Two groups of accessions were depicted (closed circles), one of Mesoamerican origin (light gray/orange) and the other of Andean origin (dark gray/blue). Open circles (in green) refer to the accessions of admixed origin between the original gene pools.

TABLE 1. Response of Portuguese common bean accessions to Fusarium wilt according to the gene pool of origin ${ }^{\mathrm{a}}$

\begin{tabular}{lcccc}
\hline & & \multicolumn{2}{c}{ Number of common bean accessions } \\
\cline { 3 - 5 } Gene pool of origin $^{\mathrm{b}}$ & AUDPC range & DS30 = 1 resistant & DS30 = 2-3 intermediate & 40 \\
Andean & $27.8-104.8$ & 11 & 14 & DS30 $=4-5$ susceptible \\
Mesoamerican & $32.1-102.4$ & 0 & 12 & 13 \\
Admixed & $27.8-105.1$ & 3 & 8 \\
\hline
\end{tabular}

a The minimum and maximum area under disease progress curve (AUDPC) values and disease severity scored at 30 days after inoculation (DS30) are shown.

${ }^{\mathrm{b}}$ Gene pool of origin resulting from the structure analysis performed together with gene pool representatives (Leitão et al. 2017). 
from CIAT that have been used for race determination in $F$. oxysporum $\mathrm{f}$. sp. phaseoli, revealed the high virulence of FOP-SP1 race 6 isolate (Alves-Santos et al. 2002). All screened cultivars in that study were susceptible to this isolate, even the ones that had been described as resistant against other $F$. oxysporum f. sp. phaseoli isolates.

The Mesoamerican lines from CIAT, SER16, and Tio Canela-75, used in our study for international comparison, were found intermediate and susceptible, respectively. This suggests that SER16, a recognized drought-tolerant elite line (Polania et al. 2016b), may also contain genes (common or not to drought tolerance) that confer resistance to this $F$. oxysporum f. sp. phaseoli race. Indeed, a transcriptomic analysis revealed that drought stress and vascular pathogen infection induced in chickpea shared differentially expressed genes associated to the cell wall and alkaloid biosynthesis, defense related-proteins, and osmoprotectants (Sinha et al. 2017). This might indicate that some of the mechanisms induced by common bean in response to both stresses are coincident, but further investigation is needed.

In the present study, we observed a range of plant responses to Fusarium wilt inoculation from highly resistant to highly susceptible. Such continuity supports the existence of quantitative resistance mechanisms in common bean against $F$. oxysporum $\mathrm{f}$. sp. phaseoli race 6 . This quantitative nature was already suggested for F. oxysporum f. sp. phaseoli race 4 (Cross et al. 2000), with the involvement of several genes, each contributing a small to moderate effect in the resistance level. Both dominant monogenic and oligogenic resistance to $F$. oxysporum have been observed in various legume species (Infantino et al. 2006; Rispail and Rubiales 2014; Sharma et al. 2005). In common bean, studies of the inheritance of resistance to Fusarium wilt have been performed with segregating populations derived from contrasting cultivar crosses and $F$. oxysporum $\mathrm{f}$. sp. phaseoli races isolated from particular geographic regions (Batista et al. 2017; Fall et al. 2001; Xue et al. 2015). Some major resistance genes and QTLs were identified against $F$. oxysporum $\mathrm{f}$. sp. phaseoli races 1 and 3 , and against race 4 recessive and polygenic resistance were also reported (Fall et al. 2001; Schwartz and Otto 2005). More recently, Batista and colleagues (2017) classified common bean resistance to a putative new $F$. oxysporum f. sp. phaseoli race as dominant and governed by a few major genes and polygenes.

In our study, we identified a total of nine different associated genomic regions using a $-\log _{10}(P) \geq 3$ (marginal Wald test). Three of the nine SNPs were associated with the three traits DS30, AUDPC, and DSr, another four with both DS30 and AUDPC, and two with only DSr, for a total of 19 SNP-trait associations. Considering the

TABLE 2. Pearson linear correlations between disease severity scored at 30 days after inoculation (DS30), area under disease progress curve (AUDPC), and disease progress rate (DSr), measured in 162 Portuguese common bean accessions

\begin{tabular}{lccc}
\hline & DS30 & AUDPC & DSr \\
\hline DS30 & - & & \\
AUDPC & 0.9683 & - & - \\
DSr & 0.8152 & 0.7019 & - \\
\hline
\end{tabular}

TABLE 3. Variance components and broad sense heritability for the three traits measured in 148 Portuguese common bean accessions

\begin{tabular}{lcccc}
\hline & \multicolumn{3}{c}{ Variance components } & \\
\cline { 2 - 4 } Trait $^{\mathrm{a}}$ & $\sigma_{\text {genotype }}^{2}$ & $\sigma_{\text {block }}^{2}$ & $\sigma_{\text {residual }}^{2}$ & $h^{2}$ heritability (\%) \\
\hline DS30 & 1.0517 & 0.3812 & 0.475 & 71.5 \\
AUDPC & 406.9 & 143.1 & 201.5 & 69.6 \\
DSr & 0.00877 & 0.00000 & 0.0185 & 40.8
\end{tabular}

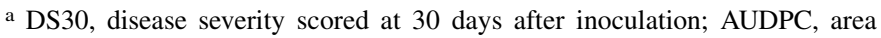
under disease progress curve; DSr, disease progress rate. more stringent LD-adjusted Bonferroni correction, these detected associations are to be considered only as suggestive associations. Nevertheless, among the Manhattan plots, the threshold of $-\log _{10}(P)=3$ was clearly above the association background noise, and, on the other hand, the Q-Q plots did not show much inflation, indicating the interest of the nine detected associated genomic regions. The complexity of the measured traits, potentially controlled by multiple genes with small effects on Fusarium wilt resistance, together with the small association panel, probably limited the power to detect SNP-trait associations (Korte and Farlow 2013, Pasam et al. 2012). Still, the associations detected in the present study were useful for identifying candidate loci related to disease resistance. These candidates need now to be validated by gene expression functional studies in contrasting accessions and in follow-up studies using different genetic backgrounds or different environments or through the development and use of segregating biparental populations (Ioannidis et al. 2009).

Most of the associations were coincident for the three traits analyzed (AUDPC, DS30, and DSr), reflecting the high correlation between the traits. Two associations were unique for DSr on chromosome Pv05. Although the proportion of the observed phenotypic variance explained by each significant SNP-trait association ranged from 4.7 to $7.2 \%$, the favorable allele of the associations with the highest effect corresponded to an increase in Fusarium wilt resistance of $16 \%$ and a reduction in the disease progress rate of $19 \%$. This suggests that, even with moderate trait heritabilities (0.72 for DS30, 0.70 for AUDPC, and 0.41 for DSr) because of the high influence of the environmental variability, improvements can be attained through selection within this Portuguese germplasm.

The average frequency of the favorable allele of the nine SNPs associated with Fusarium wilt resistance varied according to the gene pool of origin of the common bean accessions. For most of the resistance-associated SNPs, the accessions of Mesoamerican origin had higher frequencies of the allele conferring resistance, with the exception of the two associated SNPs identified on chromosome Pv08. This indicates that there is room in the accessions of Andean origin to improve their resistance, by introgression of interesting resistance alleles from Mesoamerican lines into Andean breeding germplasm. However, the smaller number of Portuguese accessions of Mesoamerican origin in the association panel in relation to the accessions of Andean origin (25 versus 97) could have biased these results. Although the Portuguese common bean germplasm is constituted predominantly by accessions of Andean origin, one third of the accessions have admixed genetic origin and might represent putative hybrids among gene pools from the two original centers of domestication (Leitão et al. 2017). Thus, not only the accessions of Andean or Mesoamerican origin identified as resistant to $F$. oxysporum f. sp. phaseoli infection may be useful for common bean resistance breeding within each particular gene pool, but also the resistant accessions with admixture nature may contain novel and advantageous genetic combinations for gene pool breeding. We identified among the accessions of admixed genetic origin favorable SNP alleles for Fusarium wilt resistance that can reflect a positive selection contributing to adaptation to the local environment. It is known that coevolution of host and pathogens has led to the development of isolates that infect mainly the common beans from one particular gene pool (Geffroy et al. 1999; Kelly et al. 2003). The development of common bean cultivars with pyramided genes for $F$. oxysporum f. sp. phaseoli resistance identified in common bean accessions from different origins is accordingly an effective strategy for durable resistance because the pathogen cannot easily overcome the resistance conferred by several genes (Batista et al. 2017; Miklas et al. 2006).

Six of the nine resistance-associated SNPs were located in putative candidate genes, according to the common bean reference genome (v2.1). DART03480 and SNP01469, both on chromosome $\mathrm{Pv} 04$, were located in genes that code for a pyruvate kinase protein 
and for a nuclear pore membrane glycoprotein (Nup210, gp210related), respectively. Pyruvate kinase is an enzyme that catalyzes the conversion of phosphoenolpyruvate and ADP to pyruvate and ATP in glycolysis and plays a role in amino acid and secondary metabolite (such as terpenes) biosynthesis (Ambasht and Kayastha
2002). Several studies reported the accumulation of amino acids such as valine, leucine, and tyrosine during plant defense responses; however, knowledge about the mechanisms behind reconfiguration of the plant metabolism when facing a pathogen is still scarce (Rojas et al. 2014). On the other hand, the role of nuclear pore complex in
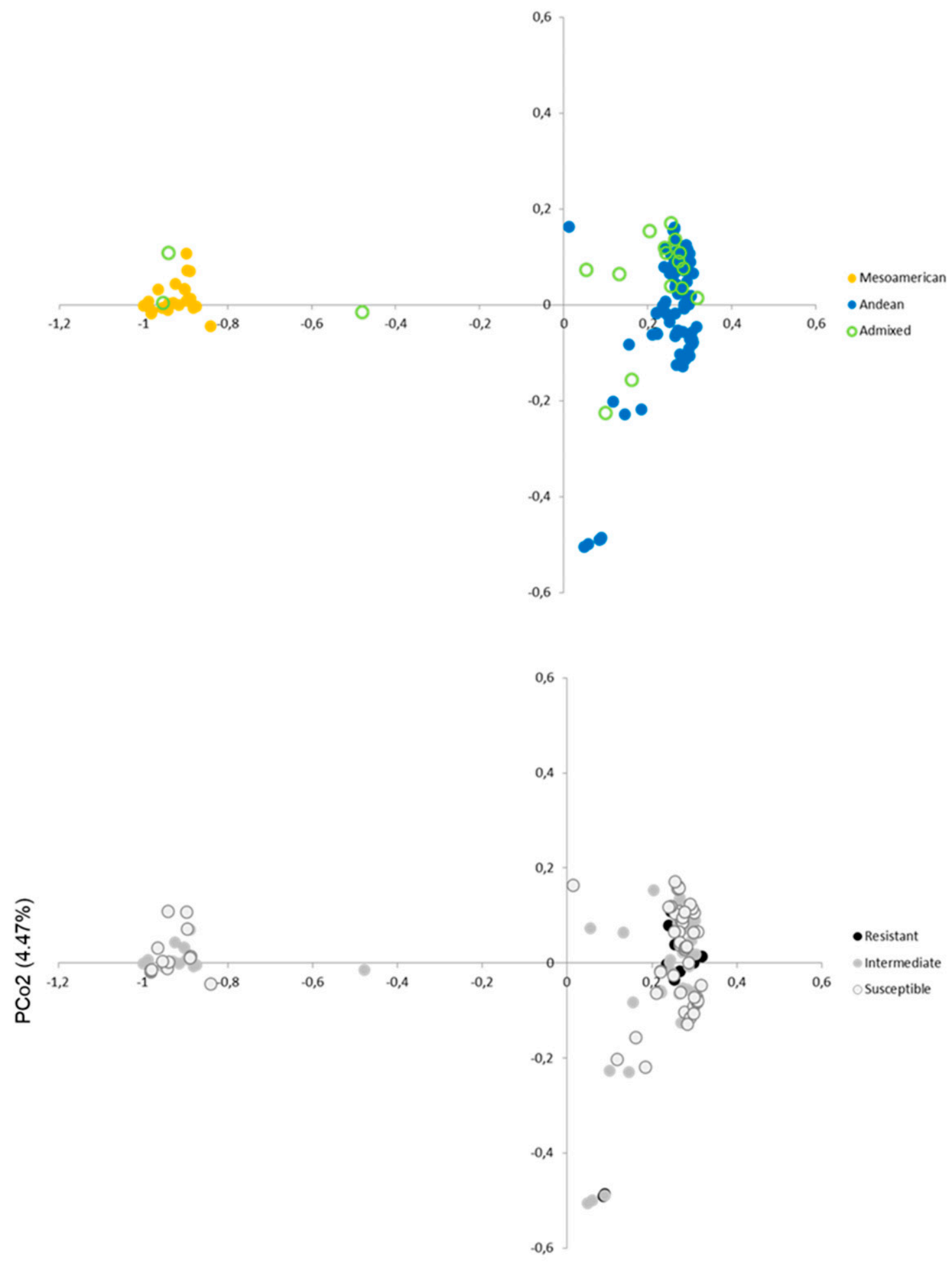

PCo1 $(65.71 \%)$

Fig. 5. Principal coordinate analysis (PCoA) of the Portuguese common bean collection based on the genotypic profile of 133 accessions using 454 singlenucleotide polymorphism (SNP) markers evenly distributed along the genome. In the top plot, the accessions are colored according to the structure analysis performed together with gene pool representatives (Leitão et al. 2017). Two groups of accessions were depicted (closed circles), one of Mesoamerican origin (light gray/orange) and another of Andean origin (dark gray/blue). Open circles (in green) refer to the accessions of admixed origin between the original gene pools. In the bottom plot, the same PCoA is displayed but with the accessions colored according to their response to Fusarium wilt infection (FOP-SP1, race 6): resistant in black, intermediate in dark gray, and susceptible in light gray. 
nucleocytoplasmic trafficking has been described not only in growth and developmental processes but also in plant response to biotic stresses (Cheng et al. 2009; Yang et al. 2017). For example, in Nicotiana benthamiana a nuclear pore protein (NbNup75) is involved in ethylene signaling and induction of defense responses such as the production of phytoalexins or programmed cell death that limits the pathogen spread (Ohtsu et al. 2014). Of note, the release of phytoalexins to inhibit Fusarium wilt progression was already described in chickpea and pea (Bani et al. 2018; Cachinero et al. 2002). Furthermore, in Arabidopsis, the transmembrane nucleoporin constitutive expresser of pathogenesisrelated genes 5 associates with nuclear pore complex and regulates an essential inhibitory mechanism of ethylenetriggered immunity/programmed cell death (Gu et al. 2016),
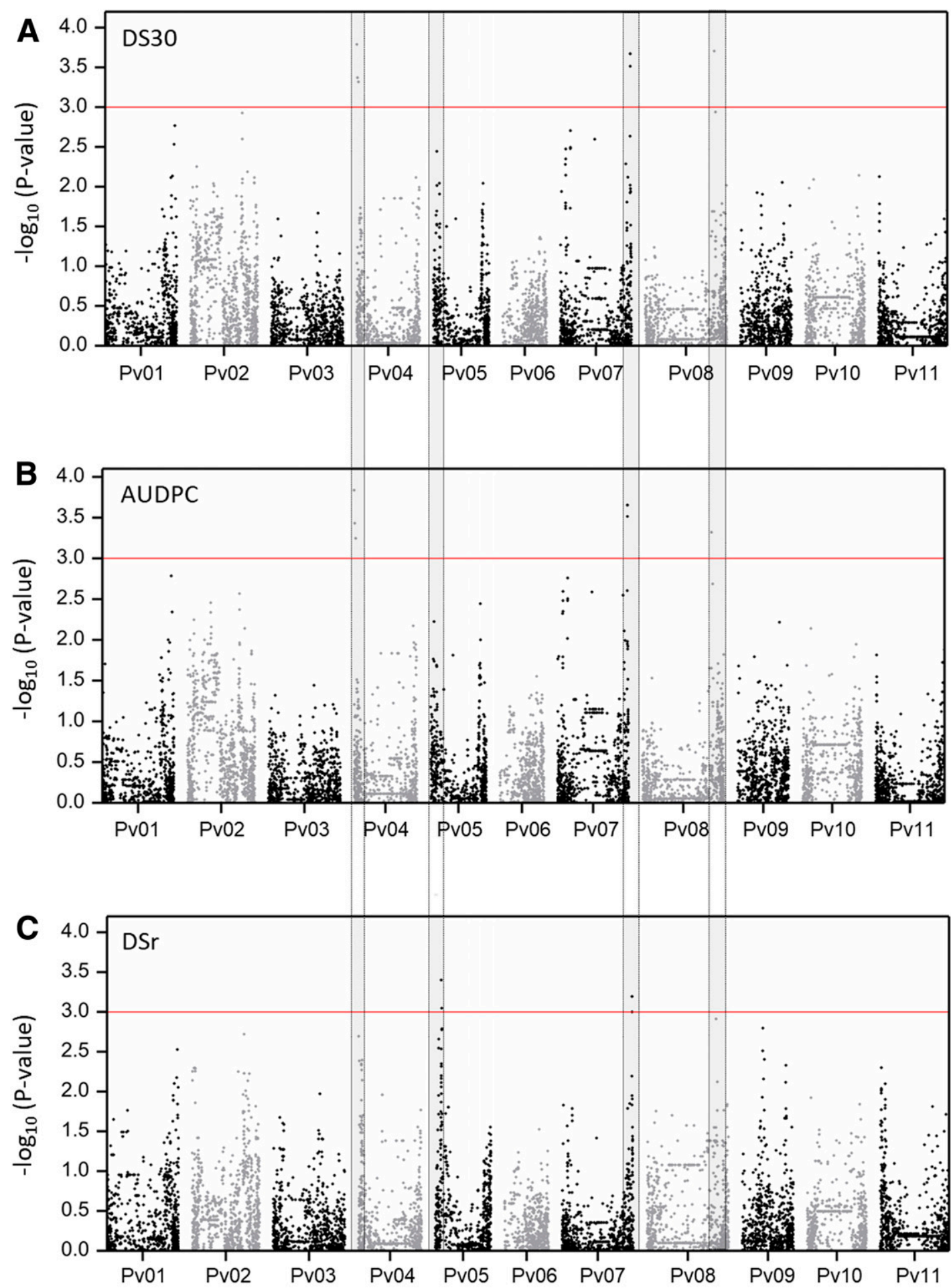

\section{Phaseolus vulgaris chromosomes}

Fig. 6. Manhattan plot depicting the genome-wide association results for A, Fusarium wilt DS30, B, area under disease progress curve (AUDPC), and C, disease progress rate (DSr) of a panel of 133 Portuguese common bean accessions. The $y$-axis represents the $-\log _{10}(P$ value $)$ of 9,825 single-nucleotide polymorphisms (SNPs), and the $x$-axis shows their chromosomal positions. The horizontal red line indicates a threshold of significance of $-\log _{10}(P$ value $)=3$. The four highlighted vertical columns correspond to genomic regions with significantly associated SNPs. 


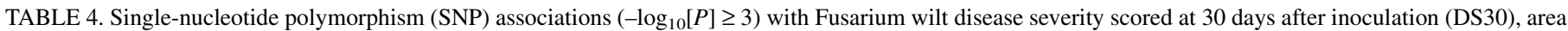

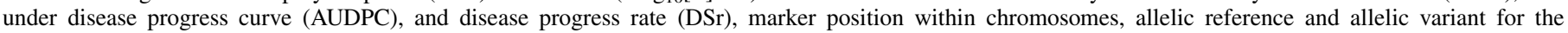

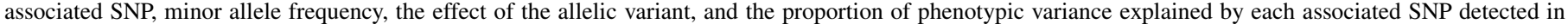
a panel of 133 Portuguese common bean accessions

\begin{tabular}{|c|c|c|c|c|c|c|c|c|c|c|c|}
\hline $\begin{array}{l}\text { Marker } \\
\text { name }\end{array}$ & Trait & $\begin{array}{c}-\log _{10} \\
(P)\end{array}$ & Original $P$ & $\begin{array}{c}\text { Adjusted BY } \\
P^{\mathrm{a}}\end{array}$ & $\begin{array}{c}\text { Phaseolus } \\
\text { vulgaris } \\
\text { chromosome }\end{array}$ & $\begin{array}{c}\text { Position } \\
\text { (Mbp) }\end{array}$ & $\begin{array}{l}\text { Allelic } \\
\text { reference }\end{array}$ & $\begin{array}{l}\text { Allelic } \\
\text { variant }\end{array}$ & $\begin{array}{l}\text { Minor allele } \\
\text { frequency }\end{array}$ & $\begin{array}{l}\text { Effect of the } \\
\text { allelic variant }{ }^{\mathrm{b}}\end{array}$ & $\begin{array}{c}V_{\mathrm{QTL}} / \\
V_{\text {pheno }}{ }^{\mathrm{c}}\end{array}$ \\
\hline \multirow[t]{2}{*}{ DART03480 } & DS30 & 3.79 & $1.625 \times 10^{-4}$ & $5.630 \times 10^{-5}$ & \multirow[t]{2}{*}{ Pv04 } & \multirow[t]{2}{*}{0.0521} & \multirow[t]{2}{*}{ G } & \multirow[t]{2}{*}{$\mathrm{T}$} & \multirow[t]{2}{*}{0.19} & 0.565 & 0.0602 \\
\hline & AUDPC & 3.84 & $1.457 \times 10^{-4}$ & $5.630 \times 10^{-5}$ & & & & & & 11.54 & 0.0610 \\
\hline \multirow[t]{2}{*}{ SNP01469 } & DS30 & 3.37 & $4.262 \times 10^{-4}$ & $3.378 \times 10^{-4}$ & \multirow[t]{2}{*}{ Pv04 } & \multirow[t]{2}{*}{0.4735} & \multirow[t]{2}{*}{$\mathrm{C}$} & \multirow[t]{2}{*}{ A } & \multirow[t]{2}{*}{0.18} & 0.545 & 0.0544 \\
\hline & AUDPC & 3.32 & $4.779 \times 10^{-4}$ & $3.378 \times 10^{-4}$ & & & & & & 11.16 & 0.0555 \\
\hline \multirow[t]{2}{*}{ SNP01487 } & DS30 & 3.32 & $4.810 \times 10^{-4}$ & $3.941 \times 10^{-4}$ & \multirow[t]{2}{*}{ Pv04 } & \multirow[t]{2}{*}{2.040} & \multirow[t]{2}{*}{$\mathrm{C}$} & \multirow[t]{2}{*}{ A } & \multirow[t]{2}{*}{0.16} & 0.605 & 0.0593 \\
\hline & AUDPC & 3.25 & $5.673 \times 10^{-4}$ & $3.941 \times 10^{-4}$ & & & & & & 12.13 & 0.0579 \\
\hline DART04561 & $\mathrm{DSr}$ & 3.40 & $3.975 \times 10^{-4}$ & $5.630 \times 10^{-5}$ & Pv05 & 4.433 & A & G & 0.33 & 0.0563 & 0.0644 \\
\hline SNP02051 & $\mathrm{DSr}$ & 3.05 & $8.966 \times 10^{-4}$ & $2.251 \times 10^{-4}$ & Pv05 & 4.781 & A & $\mathrm{G}$ & 0.27 & -0.0500 & 0.0472 \\
\hline \multirow[t]{3}{*}{ SNP03304 } & DS30 & 3.67 & $2.133 \times 10^{-4}$ & $1.689 \times 10^{-4}$ & \multirow[t]{3}{*}{ Pv07 } & \multirow[t]{3}{*}{39.04} & \multirow[t]{3}{*}{$\mathrm{C}$} & \multirow[t]{3}{*}{$\mathrm{T}$} & \multirow[t]{3}{*}{0.23} & -0.574 & 0.0718 \\
\hline & AUDPC & 3.65 & $2.222 \times 10^{-4}$ & $1.689 \times 10^{-4}$ & & & & & & -11.59 & 0.0709 \\
\hline & $\mathrm{DSr}$ & 3.19 & $6.395 \times 10^{-4}$ & $1.126 \times 10^{-4}$ & & & & & & -0.0569 & 0.0526 \\
\hline \multirow[t]{3}{*}{ SNP03305 } & DS30 & 3.51 & $3.061 \times 10^{-4}$ & $2.815 \times 10^{-4}$ & \multirow[t]{3}{*}{ Pv07 } & \multirow[t]{3}{*}{39.11} & \multirow[t]{3}{*}{ G } & \multirow[t]{3}{*}{ A } & \multirow[t]{3}{*}{0.24} & -0.562 & 0.0702 \\
\hline & AUDPC & 3.43 & $3.709 \times 10^{-4}$ & $2.815 \times 10^{-4}$ & & & & & & -11.37 & 0.0697 \\
\hline & $\mathrm{DSr}$ & 3.00 & $9.987 \times 10^{-4}$ & $2.252 \times 10^{-4}$ & & & & & & -0.0550 & 0.0502 \\
\hline \multirow[t]{3}{*}{ SNP03306 } & DS30 & 3.67 & $2.133 \times 10^{-4}$ & $2.252 \times 10^{-4}$ & \multirow[t]{3}{*}{ Pv07 } & \multirow[t]{3}{*}{39.17} & $\mathrm{C}$ & $\mathrm{T}$ & 0.23 & -0.574 & 0.0718 \\
\hline & AUDPC & 3.51 & $3.059 \times 10^{-4}$ & $2.252 \times 10^{-4}$ & & & & & & -11.59 & 0.0709 \\
\hline & $\mathrm{DSr}$ & 3.19 & $6.395 \times 10^{-4}$ & $1.689 \times 10^{-4}$ & & & & & & -0.0569 & 0.0526 \\
\hline DART07926 & DS30 & 3.71 & $1.974 \times 10^{-4}$ & $1.126 \times 10^{-4}$ & Pv08 & 54.08 & A & $\mathrm{T}$ & 0.23 & -0.571 & 0.0702 \\
\hline & AUDPC & 3.65 & $2.221 \times 10^{-4}$ & $1.689 \times 10^{-4}$ & & & & & & -10.91 & 0.0621 \\
\hline
\end{tabular}

a Adjusted $P$ value for multiple comparisons according to Benjamini-Yekutieli approach.

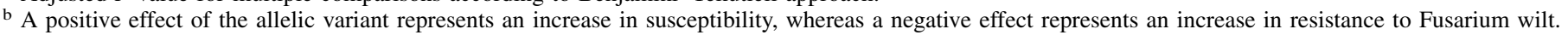

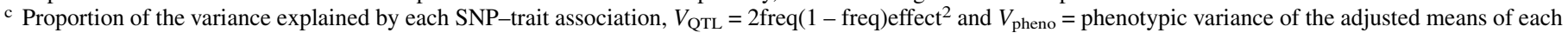
trait.

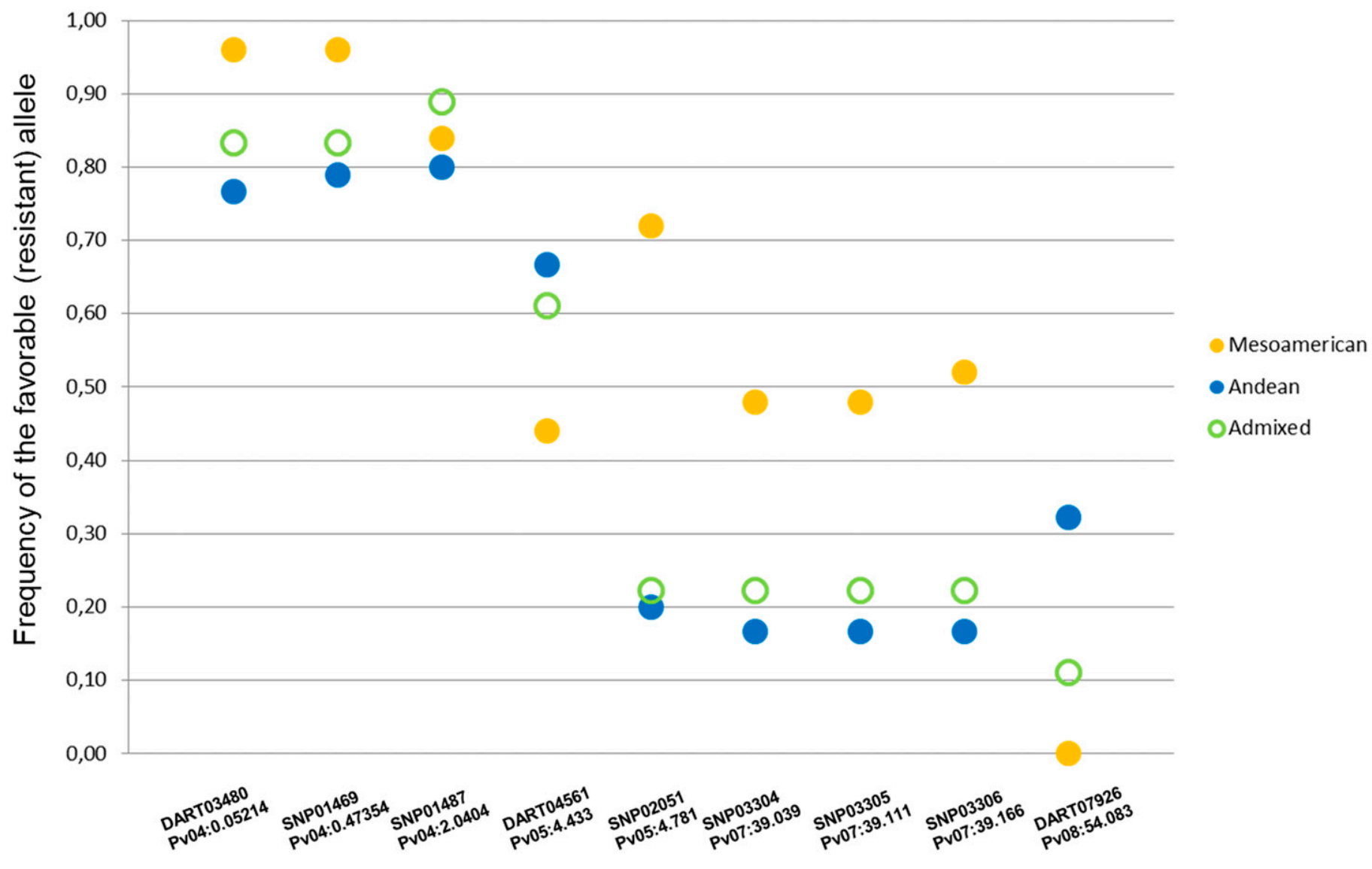

SNPs associated in chromosomal order

Fig. 7. Frequency of the favorable (conferring resistance) allele of the nine single-nucleotide polymorphisms (SNPs) associated with Fusarium wilt area under disease progress curve (AUDPC), disease severity at 30 days after inoculation (DS30), and disease progress rate (DSr) according to the main gene pool of origin of the Portuguese common bean accessions (previously determined in Leitão et al. 2017). Each SNP marker is identified in the $x$-axis by its name and position in the chromosome (in Mbp). 
vital for host recognition of pathogen virulence effectors to induce defense. SNP03305, on chromosome Pv07, was also located in a candidate gene that codes for a protein involved in programmed cell death (preribosomal RNA processing protein Rrp5). Programmed cell death is a well-described mechanism in plantpathogen interactions (Huysmans et al. 2017) with an important role in resistance response. In fact, the hypersensitive response, eliciting localized cell death at the site of the pathogen attack, is often triggered to restrict biotrophic and hemibiotrophic fungus growth and had already been observed in different $F$. oxysporum-plant interactions (Cachinero et al. 2002; Chen et al. 2014; Swarupa et al. 2014; Xue et al. 2015).

Interestingly, some of the loci associated with Fusarium wilt detected in this study were located in genomic regions that have been previously associated with resistance to other diseases in common bean. For instance, the aforementioned SNP01469 and SNP01487 (with no candidate gene associated) colocalized, on chromosome Pv04, with a major QTL for bacterial resistance. This QTL (HB4.2) confers resistance to multiple races of Pseudomonas syringae pv. phaseolicola, the bacterium that causes halo blight (Tock et al. 2017). Within the mapping interval of this QTL, some genes were identified and predicted to encode proteins with nucleotide-binding site leucine-rich repeat domains, known to enable pathogen detection and defense signaling and typically associated with hypersensitive cell death (Tock et al. 2017). In the same genomic region, the Co-34/Phg-3 locus, which confers resistance to leaf angular spot caused by Pseudocercospora griseola (Sacc.), was also identified (Valentini et al. 2017). Among the candidate genes for the Co-34/Phg-3 locus, one contains the serine/threonine kinase domain whose function has been correlated to hypersensitive response and $\mathrm{H}_{2} \mathrm{O}_{2}$ accumulation (Cao et al.
2011). In our study, we did not microscopically analyze the roots after $F$. oxysporum f. sp. phaseoli inoculation. That could be a necessary follow-up histological task to monitor and confirm the presence of hypersensitive cell death in the resistant accessions of the Portuguese collection.

DART04561 on chromosome Pv05, and SNP03306 on chromosome Pv07 are located in candidate genes that code for precursor mRNA-related proteins. Whereas the first codes for a prp39-related protein of unknown function, the second is located in a candidate gene that codes for precursor mRNA prp19-related splicing factor. Alternative splicing has been described as an important mechanism in DNA damage response, plant immunity, and defense (Lenzken et al. 2013; Shang et al. 2017; Yang et al. 2014). Moreover, in Arabidopsis thaliana, the role of the spliceosomal component prp19 was linked to pathogen defense (Meyer et al. 2015).

DART07926 (on chromosome Pv08) is located in a candidate gene that coded for a reticulon-like protein b1, whose absence was found to increase susceptibility to pathogens in Arabidopsis by regulating the intracellular trafficking and activity of bacterial flagellin immune receptor (FLS2) (Lee et al. 2011). Downstream to FLS2, essential signal transduction events by mitogen-activated protein kinase cascades are well known to confer resistance to both bacterial and fungal pathogens (Asai et al. 2002), including $F$. oxysporum (Wang et al. 2015).

In addition to the aforementioned SNP01487, SNP2051 (on chromosome Pv05) and SNP03304 (on chromosome Pv07) had no associated candidate gene. Nevertheless, these SNPs might still be useful to select for resistance to $F$. oxysporum f. sp. phaseoli in common bean breeding. The absence of annotated candidate causal genes at these loci might be caused by genetic variability between the Portuguese common bean accessions, and the

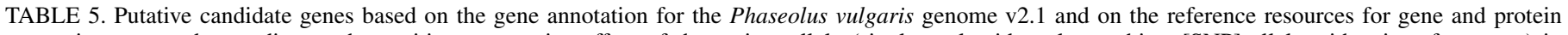

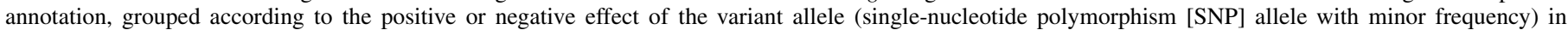
Fusarium wilt disease response ${ }^{\mathrm{a}}$

\begin{tabular}{ccc}
\hline & & Associated gene model RefGen \\
Trait & Marker name (location) & Phaseolus vulgaris v2.1 annotation (databases
\end{tabular}

Markers whose minor allele frequency SNP variant increases Fusarium wilt susceptibility AUDPC, DS30 DART03480 (Pv04: 52137 bp) Phvul.004G000800

Location (bp): Pv04: 50533..54214

AUDPC, DS30 SNP01469 (Pv04: 473538 bp) Phvul.004G006800

Location (bp): Pv04: 470002..498184

AUDPC, DS30

$\mathrm{DSr}$

SNP01487 (Pv04: 2040423 bp) DART04561 (Pv05: 4432986 bp)

No candidate gene

Phvul.005G043100

Location (bp): Pv05: $4428398 . .4433095$

Markers whose minor allele frequency SNP variant increases Fusarium wilt resistance

DSr SNP02051 (Pv05: 4780996 bp) No candidate gene

AUDPC, DS30, DSr SNP03304 (Pv07: 39039345 bp) No candidate gene

AUDPC, DS30, DSr $\quad$ SNP03305 (Pv07: 39111049 bp) $\quad$ Phvul.007G270000

Location (bp): Pv07: 39106714..39126536

Phvul.007G269900 (gene model within LD block)

Location (bp): Pv07: 39100320..39101039

$\begin{array}{lll}\text { AUDPC, DS30, DSr } & \text { SNP03306 (Pv07: } 39166109 \text { bp) } & \text { Phvul.007G270500 } \\ & & \text { Location (bp): Pv07: } 39159961 . .39168244 \\ & & \\ \text { AUDPC, DS30, DSr } & \text { DART07926(Pv08: } 54083493 \text { bp) } & \begin{array}{l}\text { Phvul.008G196600 } \\ \text { Location (bp): Pv08: } 54082363 . .54086721\end{array}\end{array}$

Pyruvate kinase family protein

Pfam: PF00224, PANTHER: PTHR11817, KEGG_ENZYME: 2.7.1.40

Nuclear pore membrane, glycoprotein Nup210 (NUP210, GP210), Pfam: PF02368, PANTHER: PTHR23019, KOG1833

F1C9.34 precursor mRNA processing protein PRP39related, PTHR17204:SF28

Programmed cell death protein 11, protein rrp5 homolog, rRNA biogenesis protein RRP5 (RRP5, PDCD11) transcriptional repressor PANTHER: PTHR23270:SF10; expressed protein-related PANTHER: PTHR33057:SF33

Precursor mRNA splicing factor prp19-related

PANTHER: PTHR13889, Pfam: PF00400

Reticulon-like protein B1-related Pfam: PF02453, PANTHER: PTHR10994:SF27

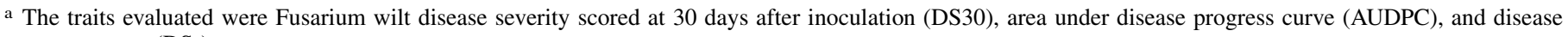
progress rate (DSr). 
Andean accession whose genome was used as reference (accession G19833).

The nine identified SNP-trait associations provided valuable insights into the genetic basis of Fusarium wilt resistance but only explained only a fraction of the total phenotypic variance. The success of association mapping in identifying markers effectively associated with the trait under study relies on how well the population structure is corrected in the association model and on the existing levels of LD. Linear mixed models can successfully correct for genetic relatedness between individuals in a population by incorporating a kinship matrix into the model and have been widely used in GWASs (Kang et al. 2010; Korte et al. 2012; Zhang et al. 2010). In common bean, LD levels were found to be stronger in the Mesoamerican gene pool and decay more rapidly in the Andean gene pool (Blair et al. 2018). In the Portuguese common bean collection analyzed here, the average intrachromosomal LD decayed to $0.1 r^{2}$ within $1.13 \mathrm{Mbp}$. A similar LD decay to $0.1 r^{2}$ within $1 \mathrm{Mbp}$ was reported recently for a common bean panel constituted by 27 Andean and 153 Mesoamerican accessions with 10,326 SNPs (Diniz et al. 2018). With 9,825 SNP markers, a significant part of the genome was covered (1 SNP/55.3 kbp), although increasing the number and distribution of markers would increase the probability of identifying additional markers in high LD with any QTLs linked to the trait. Additionally, because we are probably dealing with a polygenic trait with trait-associated variants, each with a small effect, increasing the sample size, and thus maximizing the phenotypic diversity among accessions, would increase the power to recover meaningful associations. However, most of the associated SNPs detected in our study were located inside or near candidate genes related to resistance, which reinforce the usefulness of the association panel.

The associated SNPs and putative candidate genes identified in the current study increase the number of functional markers available to facilitate resistance breeding in this major crop. Next steps will include validating the usefulness of the SNPs associated with Fusarium wilt resistance identified here, in controlled conditions, in the field with multiple locations and different years. It will be also interesting to evaluate the level of resistance of this germplasm against strains of $F$. oxysporum $\mathrm{f}$. sp. phaseoli other than FOP-SP1 race 6 to gain insights on the resistance mechanisms and genetic control against Fusarium wilt on this underused germplasm. That information is needed to determine whether the putative candidate genes found here are involved only in resistance to this specific $F$. oxysporum $\mathrm{f}$. sp. phaseoli isolate or whether they present broader resistance to different isolates. We chose FOP-SP1 race 6 because this isolate was already well described and characterized in our neighbor country, Spain, with a proven high virulence. However, it would be of interest to monitor the presence of Fusarium wilt in Portuguese fields and perform characterization and pathogenicity tests by using the local isolates.

With the present study, we unveil the potential of natural variation in the Portuguese common bean germplasm for Fusarium wilt resistance. New sources of resistance and incomplete resistance to a highly virulent $F$. oxysporum $\mathrm{f}$. sp. phaseoli strain were identified on this germplasm under oligogenic control. The associated functional molecular markers detected will support an effective marker-assisted common bean breeding for more durable resistance against Fusarium wilt.

\section{ACKNOWLEDGMENTS}

The authors are grateful to Steve Beebe, from CIAT Genetic Resources Unit, for providing seeds from the common bean lines SER16 and Tio Canela-75. We also acknowledge Maria Manuela Veloso, from Research Unit of Biotechnology and Genetic Resources, Instituto Nacional de Investigação Agrária e Veterinária, Oeiras, Portugal, for the multiplication of the Portuguese common bean collection. Sincere thanks to Moustafa Bani and Nicolas Rispail, from Instituto de Agricultura Sostenible-Consejo
Superior de Investigaciones Cientificas, Spain, for help and valuable advice during the fungal inoculations. We are also grateful to Perry Cregan, from U.S. Department of Agriculture, Agricultural Research Service, for providing support on Illumina BeadChip technology.

\section{LITERATURE CITED}

Abawi, G. S., and Pastor Corrales, M. A. 1990. Root Rots in Latin America and Africa: Diagnosis, Research Methodologies, and Management Strategies.Centro Internacional de Agricultura Tropical, Cali, Colombia.

Agrios, G. N. 1997. Plant Pathology. Academic Press, San Diego, CA.

Alves-Santos, F. M., Cordeiro-Rodrigues, L., Sayagues, J. M., Martin-Dominguez, R., Garcia-Benavides, P., Crespo, M. C., Díaz-Minguez, J. M., and Eslava, A. P. 2002. Pathogenicity and race characterization of Fusarium oxysporum $\mathrm{f}$. sp. phaseoli isolates from Spain and Greece. Plant Pathol. 51:605-611.

Ambasht, P. K., and Kayastha, A. M. 2002. Plant pyruvate kinase. Biol. Plant. 45:1-10.

Asai, T., Tena, G., Plotnikova, J., Willmann, M. R., Chiu, W.-L., Gomez-Gomez, L., Boller, T., Ausubel, F. M., and Sheen, J. 2002. MAP kinase signalling cascade in Arabidopsis innate immunity. Nature 415: 977-983.

Bani, M., Pérez-De-Luque, A., Rubiales, D., and Rispail, N. 2018. Physical and chemical barriers in root tissues contribute to quantitative resistance to Fusarium oxysporum f. sp. pisi in pea. Front. Plant Sci. 9:199.

Bani, M., Rubiales, D., and Rispail, N. 2012. A detailed evaluation method to identify sources of quantitative resistance to Fusarium oxysporum f. sp. pisi race 2 within a Pisum spp. germplasm collection. Plant Pathol. 61: 532-542.

Batista, R. O., Silva, L. C., Moura, L. M., Souza, M. H., Carneiro, P. C. S., Filho, J. L. S. C., and de Souza Carneiro, J. E. 2017. Inheritance of resistance to Fusarium wilt in common bean. Euphytica 213:133.

Benjamini, Y., and Yekutieli, D. 2001. The control of the false discovery rate in multiple testing under dependency. Ann. Statist. 29(4):1165-1188.

Blair, M. W., Cortés, A. J., Farmer, A. D., Huang, W., Ambachew, D., Penmetsa, R. V., Carrasquilla-Garcia, N., Assefa, T., and Cannon, S. B. 2018. Uneven recombination rate and linkage disequilibrium across a reference SNP map for common bean (Phaseolus vulgaris L.). PLoS One 13: e0189597.

Buruchara, R. A., and Camacho, L. 2000. Common bean reaction to Fusarium oxysporum f. sp. phaseoli, the cause of severe vascular wilt in Central Africa. J. Phytopathol. 148:39-45.

Cachinero, J. M., Hervás, A., Jiménez-Díaz, R. M., and Tena, M. 2002. Plant defence reactions against fusarium wilt in chickpea induced by incompatible race 0 of Fusarium oxysporum f. sp. ciceris and nonhost isolates of F. oxysporum. Plant Pathol. 51:765-776.

Câmara, C., Urrea, C., and Schlegel, V. 2013. Pinto beans (Phaseolus vulgaris L.) as a functional food: implications on human health. Agriculture 3: 90-111.

Cao, A., Xing, L., Wang, X., Yang, X., Wang, W., Sun, Y., Qian, C., Ni, J., Chen, Y., Liu, D., Wang, X., and Chen, P. 2011. Serine/threonine kinase gene Stpk-V, a key member of powdery mildew resistance gene $P m 21$, confers powdery mildew resistance in wheat. Proc. Natl. Acad. Sci. 108: 7727-7732.

Castillejo, M. A., Bani, M., and Rubiales, D. 2015. Understanding pea resistance mechanisms in response to Fusarium oxysporum through proteomic analysis. Phytochemistry 115:44-58.

Chen, Y. C., Kidd, B. N., Carvalhais, L. C., and Schenk, P. M. 2014. Molecular defense responses in roots and the rhizosphere against Fusarium oxysporum. Plant Signal. Behav. 9:e977710.

Cheng, R., Parker, C. C., Abney, M., and Palmer, A. A. 2013. Practical considerations regarding the use of genotype and pedigree data to model relatedness in the context of genome-wide association studies. G3 (Bethesda). 3:1861-1867.

Cheng, Y. T., Germain, H., Wiermer, M., Bi, D., Xu, F., García, A. V., Wirthmueller, L., Després, C., Parker, J. E., Zhang, Y., and Li, X. 2009. Nuclear pore complex component MOS7/Nup88 is required for innate immunity and nuclear accumulation of defense regulators in Arabidopsis. Plant Cell 21:2503-2516.

Choudhary, N., Bawa, V., Paliwal, R., Singh, B., Bhat, M. A., Mir, J. I., Gupta, M., Sofi, P. A., Thudi, M., Varshney, R. K., and Mir, R. R. 2018. Gene/QTL discovery for anthracnose in common bean (Phaseolus vulgaris L.) from North-western Himalayas. PLoS One 13:e0191700.

Cross, H., Brick, M. A., Schwartz, H. F., Panella, L. W., and Byrne, P. F. 2000. Inheritance of resistance to Fusarium wilt in two common bean races. Crop Sci. 40:954-958.

Di Pietro, A., Madrid, M. P., Caracuel, Z., Delgado-Jarana, J., and Roncero, M. I. G. 2003. Fusarium oxysporum: exploring the molecular arsenal of a vascular wilt fungus. Mol. Plant Pathol. 4:315-325. 
Diniz, A. L., Giordani, W., Costa, Z. P., Margarido, G. R. A., Perseguini, J. M. K. C., Benchimol-Reis, L. L., Chiorato, A. F., Garcia, A. A. F., and Vieira, M. L. C. 2018. Evidence for strong kinship influence on the extent of linkage disequilibrium in cultivated common beans. Genes (Basel) 10:5.

Dodds, P. N., and Rathjen, J. P. 2010. Plant immunity: towards an integrated view of plant-pathogen interactions. Nat. Rev. Genet. 11:539-548.

Duggal, P., Gillanders, E. M., Holmes, T. N., and Bailey-Wilson, J. E. 2008. Establishing an adjusted $P$-value threshold to control the family-wide type I error in genome wide association studies. BMC Genomics 9:516.

Estatísticas Agrícolas. 2017. Instituto Nacional de Estatística. www.ine.pt

Fall, A. L., Byrne, P. F., Jung, G., Coyne, D. P., Brick, M. A., and Schwartz, H. F. 2001. Detection and mapping of a major locus for Fusarium wilt resistance in common bean. Crop Sci. 41:1494-1498.

Garcés-Fiallos, F. R., de Borba, M. C., Schmidt, É. C., Bouzon, Z. L., and Stadnik, M. J. 2017. Delayed upward colonization of xylem vessels is associated with resistance of common bean to Fusarium oxysporum f. sp. phaseoli. Eur. J. Plant Pathol. 149:477-489.

Geffroy, V., Sicard, D., de Oliveira, J. C. F., Sévignac, M., Cohen, S., Gepts, P., Neema, C., Langin, T., and Dron, M. 1999. Identification of an ancestral resistance gene cluster involved in the coevolution process between Phaseolus vulgaris and its fungal pathogen Colletotrichum lindemuthianum. Mol. Plant-Microbe Interact. 12:774-784

Grayer, R. J., and Kokubun, T. 2001. Plant-fungal interactions: the search for phytoalexins and other antifungal compounds from higher plants. Phytochemistry 56:253-263.

Gu, Y., Zebell, S. G., Liang, Z., Wang, S., Kang, B.-H., and Dong, X. 2016. Nuclear pore permeabilization is a convergent signaling event in effectortriggered immunity. Cell 166:1526-1538.e11.

Guzman, P., Gilbertson, R. L., Nodari, R., Johnson, W. C., Temple, S. R., Mandala, D., Mkandawire, A. B. C., and Gepts, P. 1995. Characterization of variability in the fungus Phaeoisariopsis griseola suggests coevolution with the common bean (Phaseolus vulgaris). Phytopathology 85:600-607.

Hagerty, C. H., Cuesta-Marcos, A., Cregan, P. B., Song, Q., McClean, P., Noffsinger, S., and Myers, J. R. 2015. Mapping Fusarium solani and Aphanomyces euteiches root rot resistance and root architecture quantitative trait loci in common bean. Crop Sci. 55:1969-1977.

Haglund, W. A. 1989. A rapid method for inoculating pea seedlings with Fusarium oxysporum f. sp. pisi. Plant Dis. 73:457-458.

Hoagland, D. R., and Arnon, D. I. 1938. The Water-Culture Method for Growing Plants Without Soil.University of California, College of Agriculture Agricultural Experiment Station, Berkeley, CA.

Huysmans, M., Lema, A. S., Coll, N. S., and Nowack, M. K. 2017. Dying two deaths: programmed cell death regulation in development and disease. Curr. Opin. Plant Biol. 35:37-44.

Infantino, A., Kharrat, M., Riccioni, L., Coyne, C. J., McPhee, K. E., and Grünwald, N. J. 2006. Screening techniques and sources of resistance to root diseases in cool season food legumes. Euphytica 147:201-221.

Ioannidis, J. P. A., Thomas, G., and Daly, M. J. 2009. Validating, augmenting and refining genome-wide association signals. Nat. Rev. Genet. 10:318-329.

Kang, H. M., Sul, J. H., Service, S. K., Zaitlen, N. A., Kong, S.-y., Freimer, N. B., Sabatti, C., and Eskin, E. 2010. Variance component model to account for sample structure in genome-wide association studies. Nat. Genet. 42:348-354

Kelly, J. D., Gepts, P., Miklas, P. N., and Coyne, D. P. 2003. Tagging and mapping of genes and QTL and molecular marker-assisted selection for traits of economic importance in bean and cowpea. Field Crops Res. 82:135-154.

Kilian, A., Wenzl, P., Huttner, E., Carling, J., Xia, L., Blois, H., Caig, V., Heller-Uszynska, K., Jaccoud, D., Hopper, C., Aschenbrenner-Kilian, M., Evers, M., Peng, K., Cayla, C., Hok, P., and Uszynski, G. 2012. Diversity Arrays Technology: a generic genome profiling technology on open platforms. Pages 67-89 in: Data Production and Analysis in Population Genomics: Methods and Protocols. F. Pompanon, and A. Bonin, eds. Humana Press, Totowa, NJ.

Korte, A., and Farlow, A. 2013. The advantages and limitations of trait analysis with GWAS: a review. Plant Methods 9:29.

Korte, A., Vilhjálmsson, B. J., Segura, V., Platt, A., Long, Q., and Nordborg, M. 2012. A mixed-model approach for genome-wide association studies of correlated traits in structured populations. Nat. Genet. 44:1066-1071.

Lee, H. Y., Bowen, C. H., Popescu, G. V., Kang, H.-G., Kato, N., Ma, S., Dinesh-Kumar, S., Snyder, M., and Popescu, S. C. 2011. Arabidopsis RTNLB1 and RTNLB2 reticulon-like proteins regulate Intracellular trafficking and activity of the FLS2 immune receptor. Plant Cell 23:3374-3391.

Leitão, S. T., Dinis, M., Veloso, M. M., Šatović, Z., and Vaz Patto, M. C. 2017. Establishing the bases for introducing the unexplored Portuguese common bean germplasm into the breeding world. Front. Plant Sci. 8:1296.

Lenzken, S. C., Loffreda, A., and Barabino, S. M. L. 2013. RNA splicing: a new player in the DNA damage response. Int. J. Cell Biol. 2013:153634.

Lichtenzveig, J., Thomas, G., Oliver, R., and Singh, K. 2006. Inoculation and growth with soil borne pathogenic fungi. Pages 1-10 in: The Medicago truncatula Handbook, U. Mathesius and L. W. Sumner, eds. Noble Research Institute, Ardmore, OK.

Malosetti, M., van der Linden, C. G., Vosman, B., and van Eeuwijk, F. A. 2007. A mixed model approach to association mapping using pedigree information with an illustration of resistance to Phytophthora infestans in potato. Genetics 175:879-889.

McDonald, B. A., and Linde, C. 2002. Pathogen population genetics, evolutionary potential, and durable resistance. Annu. Rev. Phytopathol. 40: 349-379.

Meyer, K., Koester, T., and Staiger, D. 2015. Pre-mRNA splicing in plants: in vivo functions of RNA-binding proteins implicated in the splicing process. Biomolecules 5:1717-1740.

Miklas, P. N., Kelly, J. D., Beebe, S. E., and Blair, M. W. 2006. Common bean breeding for resistance against biotic and abiotic stresses: from classical to MAS breeding. Euphytica 147:105-131.

Mkandawire, A. B. C., Mabagala, R. B., Guzmán, P., Gepts, P., and Gilbertson, R. L. 2004. Genetic diversity and pathogenic variation of common blight bacteria (Xanthomonas campestris pv. phaseoli and X. campestris pv. phaseoli var. fuscans) suggests pathogen coevolution with the common bean. Phytopathology 94:593-603.

Myles, S., Peiffer, J., Brown, P. J., Ersoz, E. S., Zhang, Z., Costich, D. E., and Buckler, E. S. 2009. Association mapping: critical considerations shift from genotyping to experimental design. Plant Cell 21:2194-2202.

Nakedde, T., Ibarra-Perez, F. J., Mukankusi, C., Waines, J. G., and Kelly, J. D. 2016. Mapping of QTL associated with Fusarium root rot resistance and root architecture traits in black beans. Euphytica 212:51-63.

Niño-Sánchez, J., Tello, V., Casado-del Castillo, V., Thon, M. R., Benito, E. P., and Díaz-Mínguez, J. M. 2015. Gene expression patterns and dynamics of the colonization of common bean (Phaseolus vulgaris L.) by highly virulent and weakly virulent strains of Fusarium oxysporum. Front. Microbiol. 6: 234.

Ohtsu, M., Shibata, Y., Ojika, M., Tamura, K., Hara-Nishimura, I., Mori, H., Kawakita, K., and Takemoto, D. 2014. Nucleoporin 75 is involved in the ethylene-mediated production of phytoalexin for the resistance of Nicotiana benthamiana to Phytophthora infestans. Mol. Plant-Microbe Interact. 27: 1318-1330.

Okungbowa, F. I., and Shittu, H. O. 2012. Fusarium wilts: An overview. Environ. Res. J. 6:83-102.

Pasam, R. K., Sharma, R., Malosetti, M., van Eeuwijk, F. A., Haseneyer, G., Kilian, B., and Graner, A. 2012. Genome-wide association studies for agronomical traits in a world wide spring barley collection. BMC Plant Biol. 12:16.

Pereira, A. C., Cruz, M. F. A., Paula Júnior, T. J., Rodrigues, F. A., Carneiro, J. E. S., Vieira, R. F., and Carneiro, P. C. S. 2013. Infection process of Fusarium oxysporum f. sp. phaseoli on resistant, intermediate and susceptible bean cultivars. Trop. Plant Pathol. 38:323-328.

Perseguini, J. M. K. C., Oblessuc, P. R., Rosa, J. R. B. F., Gomes, K. A., Chiorato, A. F., Carbonell, S. A. M., Garcia, A. A. F., Vianello, R. P., and Benchimol-Reis, L. L. 2016. Genome-wide association studies of anthracnose and angular leaf spot resistance in common bean (Phaseolus vulgaris L.). PLoS One 11:e0150506.

Polania, J., Poschenrieder, C., Beebe, S., and Rao, I. M. 2016a. Effective use of water and increased dry matter partitioned to grain contribute to yield of common bean improved for drought resistance. Front. Plant Sci. 7:660

Polania, J., Rao, I. M., Cajiao, C., Rivera, M., Raatz, B., and Beebe, S. 2016b. Physiological traits associated with drought resistance in Andean and Mesoamerican genotypes of common bean (Phaseolus vulgaris L.). Euphytica 210:17-29.

Resende, R. T., Resende, M. D. V., Silva, F. F., Azevedo, C. F., Takahashi, E. K., Silva-Junior, O. B., and Grattapaglia, D. 2017. Regional heritability mapping and genome-wide association identify loci for complex growth, wood and disease resistance traits in Eucalyptus. New Phytol. 213: 1287-1300.

Rispail, N., and Rubiales, D. 2014. Identification of sources of quantitative resistance to Fusarium oxysporum f. sp. medicaginis in Medicago truncatula. Plant Dis. 98:667-673.

Rojas, C. M., Senthil-Kumar, M., Tzin, V., and Mysore, K. S. 2014. Regulation of primary plant metabolism during plant-pathogen interactions and its contribution to plant defense. Front. Plant Sci. 5:17.

Rosas, J. C., Varela, O. I., and Beaver, J. S. 1997. Registration of 'Tio Canela75' small red bean (race Mesoamerica). Crop Sci. 37:1391.

Salgado, M. O., Schwartz, H. F., and Brick, M. A. 1995. Inheritance of resistance to a Colorado race of Fusarium oxysporum f. sp. phaseoli in common beans. Plant Dis. 79:279-281.

Santos, F., Mourão, I., Costa, S. R., Brito, L. M., and Moura, L. 2017. Resistance of common bean cultivars to Fusarium oxysporum $\mathrm{f}$. $\mathrm{sp}$. phaseoli in controlled conditions. Pges 351-358 in: I Congresso Luso-Brasileiro de Horticultura. P. C. T. D. Melo, ed. Associação Portuguesa de Horticultura, Lisbon, Portugal. 
Schmutz, J., McClean, P. E., Mamidi, S., Wu, G. A., Cannon, S. B., Grimwood, J., Jenkins, J., Shu, S., Song, Q., Chavarro, C., Torres-Torres, M., Geffroy, V., Moghaddam, S. M., Gao, D., Abernathy, B., Barry, K., Blair, M., Brick, M. A., Chovatia, M., Gepts, P., Goodstein, D. M., Gonzales, M., Hellsten, U., Hyten, D. L., Jia, G., Kelly, J. D., Kudrna, D., Lee, R., Richard, M. M. S., Miklas, P. N., Osorno, J. M., Rodrigues, J., Thareau, V., Urrea, C. A., Wang, M., Yu, Y., Zhang, M., Wing, R. A., Cregan, P. B., Rokhsar, D. S., and Jackson, S. A. 2014. A reference genome for common bean and genome-wide analysis of dual domestications. Nat. Genet. 46:707-713.

Schwartz, H. F., and Otto, K. 2005. Fungal diseases of subterranean parts: Fusarium wilt (yellows). Page 120 in: H. F. Schwartz, J. R. Steadman, R. Hall, and R. L. Forster, eds. Compendium of Bean Diseases, 2nd ed. American Phytopathological Society, St. Paul, MN.

Schwartz, H. F., and Pastor-Corrales, M. A. 1980. Bean Production Problems: Disease, Insect, Soil and Climatic Constraints of Phaseolus vulgaris.Centro Internacional de Agricultura Tropical, Cali, Colombia.

Shang, X., Cao, Y., and Ma, L. 2017. Alternative splicing in plant genes: a means of regulating the environmental fitness of plants. Int. J. Mol. Sci. 18:432.

Sharma, K. D., Chen, W., and Muehlbauer, F. J. 2005. Genetics of chickpea resistance to five races of Fusarium wilt and a concise set of race differentials for Fusarium oxysporum f. sp. ciceris. Plant Dis. 89:385-390.

Sinha, R., Gupta, A., and Senthil-Kumar, M. 2017. Concurrent drought stress and vascular pathogen infection induce common and distinct transcriptomic responses in chickpea. Front. Plant Sci. 8:333.

Song, Q., Jia, G., Hyten, D. L., Jenkins, J., Hwang, E. Y., Schroeder, S. G., Osorno, J. M., Schmutz, J., Jackson, S. A., McClean, P. E., and Cregan, P. B. 2015. SNP assay development for linkage map construction, anchoring whole-genome sequence, and other genetic and genomic applications in common bean. G3 (Bethesda) 5:2285-2290.

Swarupa, V., Ravishankar, K. V., and Rekha, A. 2014. Plant defense response against Fusarium oxysporum and strategies to develop tolerant genotypes in banana. Planta 239:735-751.

Tock, A. J., Fourie, D., Walley, P. G., Holub, E. B., Soler, A., Cichy, K. A., Pastor-Corrales, M. A., Song, Q., Porch, T. G., Hart, J. P., Vasconcellos, R. C. C., Vicente, J. G., Barker, G. C., and Miklas, P. N. 2017. Genome-wide linkage and association mapping of halo blight resistance in common bean to race 6 of the globally important bacterial pathogen. Front. Plant Sci. 8:1170.

Toledo Souza, E. D., Silveira, P. M., Café Filho, A. C., and Lobo, M., Junior. 2012. Fusarium wilt incidence and common bean yield according to the preceding crop and the soil tillage system. Pesqui. Agropecu. Bras. 47: 1031-1037.

Valentini, G., Gonçalves-Vidigal, M. C., Hurtado-Gonzales, O. P., de Lima Castro, S. A., Cregan, P. B., Song, Q., and Pastor-Corrales, M. A. 2017. High-resolution mapping reveals linkage between genes in common bean cultivar Ouro Negro conferring resistance to the rust, anthracnose, and angular leaf spot diseases. Theor. Appl. Genet. 130:1705-1722.

VanRaden, P. M. 2008. Efficient methods to compute genomic predictions. J. Dairy Sci. 91:4414-4423.

VSN International. 2017. Genstat for Windows, 19th ed. VSN International, Hemel Hempstead, UK. Genstat.co.uk

Wang, Z., Jia, C., Li, J., Xu, B., and Jin, Z. 2015. Identification of six mitogenactivated protein kinase (MAPK) genes in banana (Musa acuminata L. AAA group, cv. Cavendish) under infection of Fusarium oxysporum $\mathrm{f}$. sp. cubense Tropical Race 4. Acta Physiol. Plant. 37:115.

Wimmer, V., Albrecht, T., Auinger, H.-J., and Schön, C.-C. 2012. synbreed: a framework for the analysis of genomic prediction data using R. Bioinformatics 28:2086-2087.

Wu, J., Zhu, J., Wang, L., and Wang, S. 2017. Genome-wide association study identifies NBS-LRR-encoding genes related with anthracnose and common bacterial blight in the common bean. Front. Plant Sci. 8:1398.

Xue, R., Wu, J., Zhu, Z., Wang, L., Wang, X., Wang, S., and Blair, M. W. 2015. Differentially expressed genes in resistant and susceptible common bean (Phaseolus vulgaris L.) genotypes in response to Fusarium oxysporum f. sp. phaseoli. PLoS One 10:e0127698.

Yadeta, K. A., and Thomma, B. P. H. J. 2013. The xylem as battleground for plant hosts and vascular wilt pathogens. Front. Plant Sci. 4:97.

Yang, S., Tang, F., and Zhu, H. 2014. Alternative splicing in plant immunity. Int. J. Mol. Sci. 15:10424-10445.

Yang, Y., Wang, W., Chu, Z., Zhu, J.-K., and Zhang, H. 2017. Roles of nuclear pores and nucleo-cytoplasmic trafficking in plant stress responses. Front. Plant Sci. 8:574.

Zhang, Z., Ersoz, E., Lai, C.-Q., Todhunter, R. J., Tiwari, H. K., Gore, M. A., Bradbury, P. J., Yu, J., Arnett, D. K., Ordovas, J. M., and Buckler, E. S. 2010. Mixed linear model approach adapted for genome-wide association studies. Nat. Genet. 42:355-360.

Zuiderveen, G. H., Padder, B. A., Kamfwa, K., Song, Q., and Kelly, J. D. 2016. Genome-wide association study of anthracnose resistance in Andean beans (Phaseolus vulgaris). PLoS One 11:e0156391. 